INEL-96/0483

Distribution Category: UC-425

\title{
Fusion Safety Program Annual Report Fiscal Year 1996
}

\author{
Glen R. Longhurst \\ Robert A. Anderl \\ Lee C. Cadwallader \\ W. Jon Carmack \\ J. Stephen Herring \\ Kathryn A. McCarthy \\ Brad J. Merrill \\ Richard L. Moore \\ David A. Petti \\ Steven T. Polkinghorne \\ Galen R. Smolik
}

Published December 1996

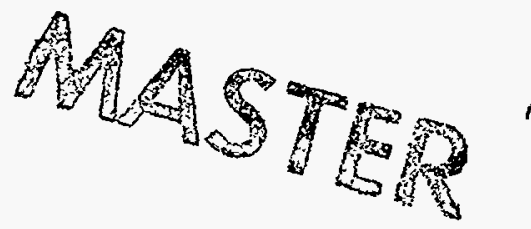

Idaho National Engineering Laboratory

Nuclear Engineering Technologies Department

Lockheed Martin Idaho Technologies Company

Idaho Falls, Idaho 83415

Prepared for the

U.S. Department of Energy

Office of Energy Research,

Under DOE Idaho Operations Office

Contract DE-AC07-94ID13223 


\section{DISCLAIMER}

This report was prepared as an account of work sponsored by an agency of the United States Government. Neither the United States Government nor any agency thereof, nor any of their employees, make any warranty, express or implied, or assumes any legal liability or responsibility for the accuracy, completeness, or usefulness of any information, apparatus, product, or process disclosed, or represents that its use would not infringe privately owned rights. Reference herein to any specific commercial product, process, or service by trade name, trademark, manufacture, or otherwise does not necessarily constitute or imply its endorsement, recommendation, or favoring by the United States Government or any agency thereof. The views and opinions of authors expressed herein do not necessarily state or reflect those of the United States Government or any agency thereof. 


\section{DISCLAIMIER}

Portions of this document may be illegible in electronic image products. Images are produced from the best available original document. 


\begin{abstract}
This report summarizes the major activities of the Fusion Safety Program in FY 1996. The Idaho National Engineering Laboratory (INEL) is the designated lead laboratory, and Lockheed Martin Idaho Technologies Company is the prime contractor for this program. The Fusion Safety Program was initiated in 1979. The objective is to perform research and develop data needed to ensure safety in fusion facilities. Activities include experiments, analysis, code development and application, and other forms of research. These activities are conducted at the INEL, at other DOE laboratories, and at other institutions. Among the technical areas covered in this report are tritium safety, chemical reactions and activation product release, risk assessment failure rate database development, and safety code development and application to fusion safety issues. Most of this work has been done in support of the International Thermonuclear Experimental Reactor (ITER). Work done for ITER this year has focused on developing the needed information for the Non-SiteSpecific Safety Report (NSSR-1). A final area of activity described is development of the new DOE Technical Standards for Safety of Magnetic Fusion Facilities.
\end{abstract}




\section{CONTENTS}

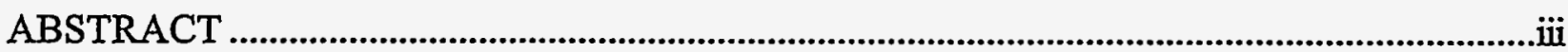

ACRONYMS........................................................................................................................

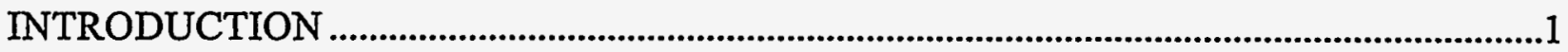

INTERNATIONAL THERMONUCLEAR EXPERIMENTAL REACTOR DESIGN AND

REGULATORY SUPPORT .........................................................................................

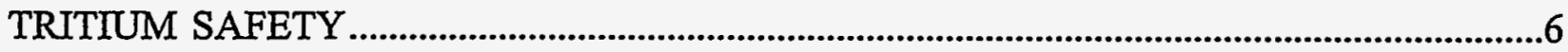

CHEMICAL REACTIVITY OF FUSTON MATERIAIS.............................................................10

ACTIVATION PRODUCT MOBILIZATION AND TRANSPORT...........................................16

FUSION SAFETY COMPUTER CODE DEVELOPMENT .........................................................21

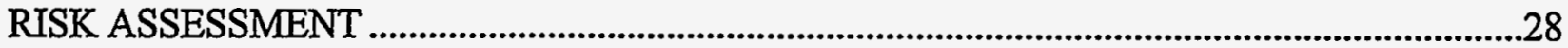

FUSION SAFETY STANDARD DEVELOPMENT.....................................................................31

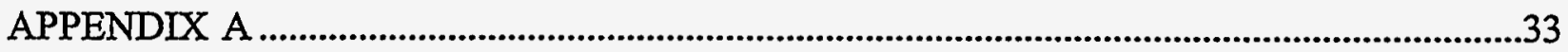

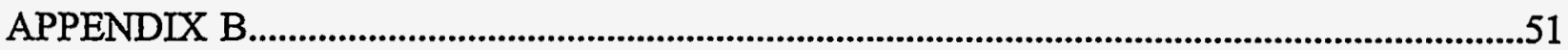

\section{FIGURES}

Figure 1. Photograph of the modified experimental system showing the target chamber, desorption chamber, loadlock chamber, and rotary/linear feedthrough for transfer of a sample between the system components......................................................

Figure 2. Sample platen with attached transferable thermocouple..................................................7

Figure 3. Comparison of hydrogen generation rates of fusion relevant materials........................12

Figure 4. Swelling of irradiated beryllium as a function of anneal temperature.

Incubation times are listed for each point.

Figure 5. Tritium release rate and relative helium signal during $1,000^{\circ} \mathrm{C}$ anneal of irradiated beryllium sample.

Figure 6. Tritium, helium, and hydrogen signals during $700^{\circ} \mathrm{C}$ irradiated beryllium test in steam. 
Figure 7. Comparison of hydrogen generation rates for irradiated and unirradiated beryllium cylinder samples from the present work with those reported by Smolik et al. and by Blumenthal and Santy.

Figure 8. Time-temperature history of $800^{\circ} \mathrm{C}$ test in steam, including surface and embedded thermocouples.

Figure 9. Comparison of selected data from FAST and VAPOR steam exposure tests at $800^{\circ} \mathrm{C}$

Figure 10. Early dose (elevated release, stability class B, $1-\mathrm{m} / \mathrm{s}$ windspeed, $1-\mathrm{km}$ site boundary) from tungsten first wall coating exposed to air per hour at temperature, per $\mathrm{m}^{2}$ surface area, no credit for any radioactivity confinement.

Figure 11. Early dose (elevated release, stability class $B, 1-\mathrm{m} / \mathrm{s}$ windspeed, $1-\mathrm{km}$ site boundary) from tungsten first wall coating exposed to steam per hour at temperature, per $\mathrm{m}^{2}$ surface area, no credit for any radioactivity confinement.

Figure 12. Schematic of the SIRENS facility modified for aerosol tests, showing source section and expansion chamber.

Figure 13. Particle size histogram for proof-of-principle test with copper source.

Figure 14. Cryostat and divertor pit pressures for the cryostat air ingress accident scenario.

Figure 15. Cryostat pressure for the cryostat water and helium ingress accident .24

Figure 16. Cryostat structure temperatures for the cryostat water and helium ingress accident scenario.

Figure 17. Airborne mass of dust, corrosion products, and tritium in generic bypass room (GBR) for in-vessel pipe break and vacuum vessel penetration bypass. .26

\section{TABLES}

Table 1. Advantages and disadvantages of various hydrogen generation measurement techniques.

Table 2. Summary of ITER in-vessel LOCA pressurization results. .25

Table 3. Generic reliability data for fire suppression systems. .29 


\section{ACRONYMS}

\begin{tabular}{ll} 
BPP & Basic Physics Phase \\
DIII-D & Doublet II-D \\
DOE & Department of Energy \\
EBR-II & Experimental Breeder Reactor II \\
EDA & Engineering Design Activity \\
EDF & Engineering Design File \\
FAST & Fusion Aerosol Source Test \\
FW & First Wall \\
FSP & Fusion Safety Program \\
GBR & Generic Bypass Room \\
HTO & Tritiated Water \\
IAEA & International Energy Agency \\
IEA & International Energy Agency \\
IFE & Inertial Fusion Energy \\
INEL & Idaho National Engineering Laboratory \\
ITER & International Thermonuclear Experimental Reactor \\
JCT & Joint Central Team \\
LOCA & Loss of Coolant Accident \\
LOVA & Loss of Vacuum Accident \\
NSSR-1 & Non-Site Specific Safety Report - 1 \\
OFES & Office of Fusion Energy Sciences \\
ORNL & Oak Ridge National Laboratory \\
PCA & Primary Candidate Alloy \\
PF & Poloidal Field \\
PFC & Plasma-Facing Component \\
PHTS & Primary Heat Transport System \\
PPPL & Princeton Plasma Physics Laboratory \\
QA & Quality Assurance \\
SAA & Safety Analysis and Assessment \\
SADL & Safety Analysis Data List \\
SIRENS & Surface Interaction Experiment at North Carolina State \\
SRMS & Steam Reactivity Measurement System \\
TAC & Technical Advisory Committee \\
TF & Toroidal Field \\
TFTR & Tokamak Fusion Test Reactor \\
TPE & Tritium Plasma Experiment \\
VAPOR & Volatilization of Activation Products Oxides Reactor \\
VDE & Vertical Displacement Event \\
WSRC & Westinghouse Savannah River Company \\
& \\
\hline
\end{tabular}




\section{FUSION SAFETY PROGRAM ANNUAL REPORT FISCAL YEAR 1996}

\section{INTRODUCTION}

Fusion power has the potential to be an important energy source while remaining inherently safe with attractive environmental features. For the full safety potential to be realized, safety must be a consideration in all aspects of design and development. In addition to incorporating design features that will enhance the safety potential of fusion systems, this requires identifying safety and environmental concerns and developing materials and technology required to implement resolutions to those concerns.

In 1979, the U.S. Department of Energy established the Fusion Safety Program (FSP) to support safety in fusion development. The Idaho National Engineering Laboratory (INEL) is the designated lead laboratory, and in 1994 Lockheed Martin Idaho Technologies became the prime contractor for this program. The program focus is to develop safety and environmental goals for fusion energy production, to identify potential safety and environmental concerns in fusion devices and approaches to resolve these concerns, and to develop technical information, risk assessment methodologies, and safety-analysis computer codes required to verify that fusion facilities are safe and environmentally attractive.

Realization of fusion's potential will result from advances in plasma physics and technology that will enhance safety, environmental, and economic attractiveness.
Plasma physicists are addressing issues of plasma disruptions, run-away electrons, emergency plasma shutdown, control of power levels, and reduction of tritium throughput. Priorities in the technology area include developing plasma-facing components that are low in activation products and have minimal threats of chemical reactions that could produce explosive quantities of hydrogen. Ultimately, low activation materials will need to be developed for all components and structures exposed to fusion neutrons. Having appropriate and useful standards in place for the design of fusion facilities for safety is also of great importance. The FSP places a high emphasis on providing technical support and guidance in these critical areas.

International cooperation has become an increasingly important part of the FSP at the INEL. In addition to participating with Japan, the European Union, and the Russian Federation in the International Thermonuclear Experimental Reactor (ITER) project, we participate in activities of the International Energy Agency.

Activities performed during this fiscal year include conducting experimental tests to develop data needed for safety analyses, developing and applying computer codes and methodology for safety analyses, and participating in studies that support safety in fusion development. Additionally, the FSP 
provided support to the ITER project by furnishing an individual to the ITER Joint Central Team and providing analysis and guidance in support of ITER safety studies. Another major activity this year has been leadership in completing the development of two DOE Technical Standards for safety of magnetic fusion facilities.

The following sections summarize work completed under each of these activities by the
INEL and participating organizations. Much of the work on ITER design studies and programmatic activities appears under the various technical areas in which the work was performed. Appendix A contains abstracts of publications based on work completed during FY 1996. Appendix B contains abstracts of Engineering Design Files (EDFs) submitted to the ITER Project. Most of the technical information developed by the Fusion Safety Program is in the EDF format. 


\title{
INTERNATIONAL THERMONUCLEAR EXPERIMENTAL REACTOR DESIGN AND REGULATORY SUPPORT
}

\author{
Researchers: D. A. Petti, J. G. Crocker, and S. J. Piet
}

The Fusion Safety Program (FSP) leads the U.S. safety and environmental effort for the International Thermonuclear Experimental Reactor (ITER) program. ITER participants are the United States, the European Union, the Russian Federation, and Japan.

As part of the ITER effort, Dr. S. J. Piet is seconded to the ITER Joint Central Team (JCT). He is the Group Leader for Safety Analysis and Assessment (SAA). Dr. D. A. Petti is the Task Area Leader for Safety and Standards within the U.S. ITER Home Team.

\section{MAJOR ACCOMPLISHMENTS}

Piet and the SAA Group are responsible for the overall technical and management integration of ITER accident safety. The Group's major accomplishment this year has been the completion of the Non-site Specific Safety Report (NSSR-1). ${ }^{1}$ The first of two such reports planned, NSSR-1 is a comprehensive plant level safety assessment that can be used by the Parties to prepare the environmental paperwork required for site selection. The ITER Technical Advisory Committee (TAC) reviewed the results of the safety assessment and said:

"It is TAC's overall assessment that major progress has been made in defining the radiological and other hazards, both during normal operation and as a result of a broad range of reference off-normal events, and in providing appropriate safety features in the ITER design. The TAC commends the JCT and the four HTs on the depth and quality of the safety analysis that is contained in the draft NSSR-1. The TAC concludes that the draft NSSR-1 satisfies the objective of providing a technical basis for assessing the safety of the ITER design to be presented in the DDR."2

NSSR-1 is another major step toward ITER regulatory approval and construction ${ }^{3}$ and toward a safety approach appropriate for fusion energy. 4,5

Piet personally coordinates the radioactivity confinement strategy. This strategy starts with equipment required for tokamak operation, including the vacuum vessel and cryostat vessel. Heat Transfer System vaults are added to provide pressure containment for pressurized water coolant, as in a fission plant. The confinement performance of surrounding volumes and the tritium plant confinement are tailored (as in a chemical plant) to the specific hazard in each volume. The result is somewhat unique, but appropriate for fusion. NSSR-1 accident analyses show that the confinement serves to meet the project dose and release limits. ${ }^{6,7}$

Piet also coordinates the ITER "source term," integrating information from several of the Home Team tasks, most notably the US Fusion Safety Program. This effort is steadily 
resolving uncertainties in the ITER source term. ${ }^{8}$

The goal of our ITER design and regulatory support work in the Fusion Safety Program is to provide ITER safety and regulatory support to the Joint Central Team (JCT) and to improve the safety of ITER by identifying key safety issues associated with the evolving ITER Engineering Design Activity (EDA). Much of the work this year was in support of NSSR-1 and is discussed later in the appropriate technical section of this report.

In addition to providing regulatory information for the ITER JCT, Dr. Petti also made a number of presentations on safety and regulatory issues to U.S. groups such as the $12^{\text {th }}$ ANS Topical Meeting on the Technology of Fusion Energy ${ }^{4}$ (invited), the American Power Conference ${ }^{9}$ (invited), the ITER Steering Committee U.S., the U.S. Home Team, the Fusion Utility Advisory Committee, and the DOE Office of Fusion Energy Sciences.

\section{FUTURE ACTIVITIES}

Our future efforts will be to continue work with the JCT on their regulatory and safety strategy for ITER and to help them complete the NSSR-2 safety documents to successfully complete the EDA and begin the transition to ITER construction. 


\section{REFERENCES}

1. ITER Joint Central Team, Non-Site Specific Safety Analysis Report (NSSR-1), November 1996 (in preparation).

2. "Summary of Deliberations," Informal Technical Assessment of ITER Safety, October 4-5, ITER San Diego Joint Work Center, 1996

3. Y. Shimomura, et al., "ITER Safety Issues," $16^{\text {th }}$ IAEA Fusion Energy Conference, Montreal, Canada, October 6-12, 1996.

4. D. A. Petti and S. J. Piet, "An Overview of ITER Safety," ANS $12^{\text {th }}$ Topical Meeting on the Technology of Fusion Energy, Reno, Nevada, June 17-21, 1996.

5. A. E. Poucet and S. J. Piet, "Safety Analysis and Design Framework in ITER," ANS International Topical Meeting on Probabilistic Safety Assessment (PSA-96): Moving Toward Risk-Based Regulation, Park City, Utah, September 29 - October 3, 1996.

6. H.-W. Bartels, et al., "Reference Event Analysis in NSSR-1," $6^{\text {th }}$ IAEA Technical Committee Meeting on Developments in Fusion Safety, JAERI, Naka, Japan, October 21-25, 1996 (to be published in the Journal of Fusion Energy).

7. W. Gulden, et al., "Analysis of ITER Accident Sequences," $19^{\text {th }}$ Symposium on Fusion Technology (SOFT), September 16-20, 1996, Lisbon, Portugal.

8. S. J. Piet, et al., "Source Term and Mobilization Assessment in NSSR-1," $6^{\text {th }}$ IAEA Technical Committee Meeting on Developments in Fusion Safety, JAERI, Naka Research Establishment, October 21-25, 1996 (to be published in the Journal of Fusion Energy).

9. D. A. Petti, "Environmental and Safety Aspects of Fusion Facilities," American Power Conference 58 ${ }^{\text {th }}$ Annual Meeting, April 1996, Chicago IL. 


\section{TRITIUM SAFETY}

\section{Researchers: G. R. Longhurst, R. A. Anderl, M. A. Oates, and R. J. Pawelko-INEL}

Our tritium safety work is focused on the International Thermonuclear Experimental Reactor (ITER) goals of keeping routine and accidental tritium releases within acceptable limits, thus avoiding the need for evacuation of the surrounding population. We are pursuing a broad spectrum of tritium-related studies, including continued development of the Idaho National Engineering Laboratory tritium laboratory capabilities; plasma-driven permeation studies involving plasma-facing materials; applications of the TMAP4 code, particularly with regard to tritium inventories in ITER; and assisting in the interpretation of experimental data from the Tritium Plasma Experiment (TPE) and other experiments.

\section{Major Accomplishments}

Tritium Research Laboratory. A new target/heater assembly and postimplantation thermal desorption system was installed in the ion-implantation system. This system permits exposure of a heated specimen to the deuterium ion beam and rapid cooling of the specimen to ambient temperature to retain the implanted deuterium. The specimen may then be transported under vacuum to an ultra-high vacuum chamber where the deuterium release behavior is measured as the specimen is subject to a thermal transient that simulates an accident scenario for ITER. The modification to the experimental system was installed early in FY 1996. Figure 1 shows the updated implantation facility.

\section{Deuterium Implantation/Permeation}

Studies. Using the new implantation facilities, implantation/thermal desorption experiments were conducted on beryllium samples, some of which had been coated with carbon. ${ }^{1}$ Coating thicknesses were 100,500 , and $1,000 \AA$. Heat treatment of the sample with the $100-\AA$ coating at $400^{\circ} \mathrm{C}$ for $2 \mathrm{hr}$ revealed that beryllium had diffused through the coating leaving more $\mathrm{Be}$ than $\mathrm{C}$ in the coating layer. Figure 2 shows the samples installed in the holding and heating fixture inside the experiment.

Deuterium implantation / thermal desorption experiments for a bare $\mathrm{Be}$ sample and for Be samples coated with $\sim 500$ and $\sim 1,000 \AA$ of carbon revealed differences in deuterium retention and postimplantation release behavior. For comparable implantation conditions (sample temperature of $400^{\circ} \mathrm{C}$ and an incident deuterium flux of $\sim 6 \times 10^{19} \mathrm{D} / \mathrm{m}^{2} \mathrm{~s}$ ), the quantity of deuterium retained in the bare Be sample was about $25 \%$ less than in the Ccoated sample. In thermal desorption tests, the majority of deuterium was released at a lower temperature for the bare $\mathrm{Be}$ than for $\mathrm{C}$ coated Be.

Interpretation of TPE Experimental Data. Experiments conducted on the TPE, located at the Tritium Systems Test Assembly, Los Alamos National Laboratory, showed that the deuterium and tritium retention in plasmafacingberyllium was almost independent of the intensity of the ion flux to the surface. ${ }^{2}$ This 


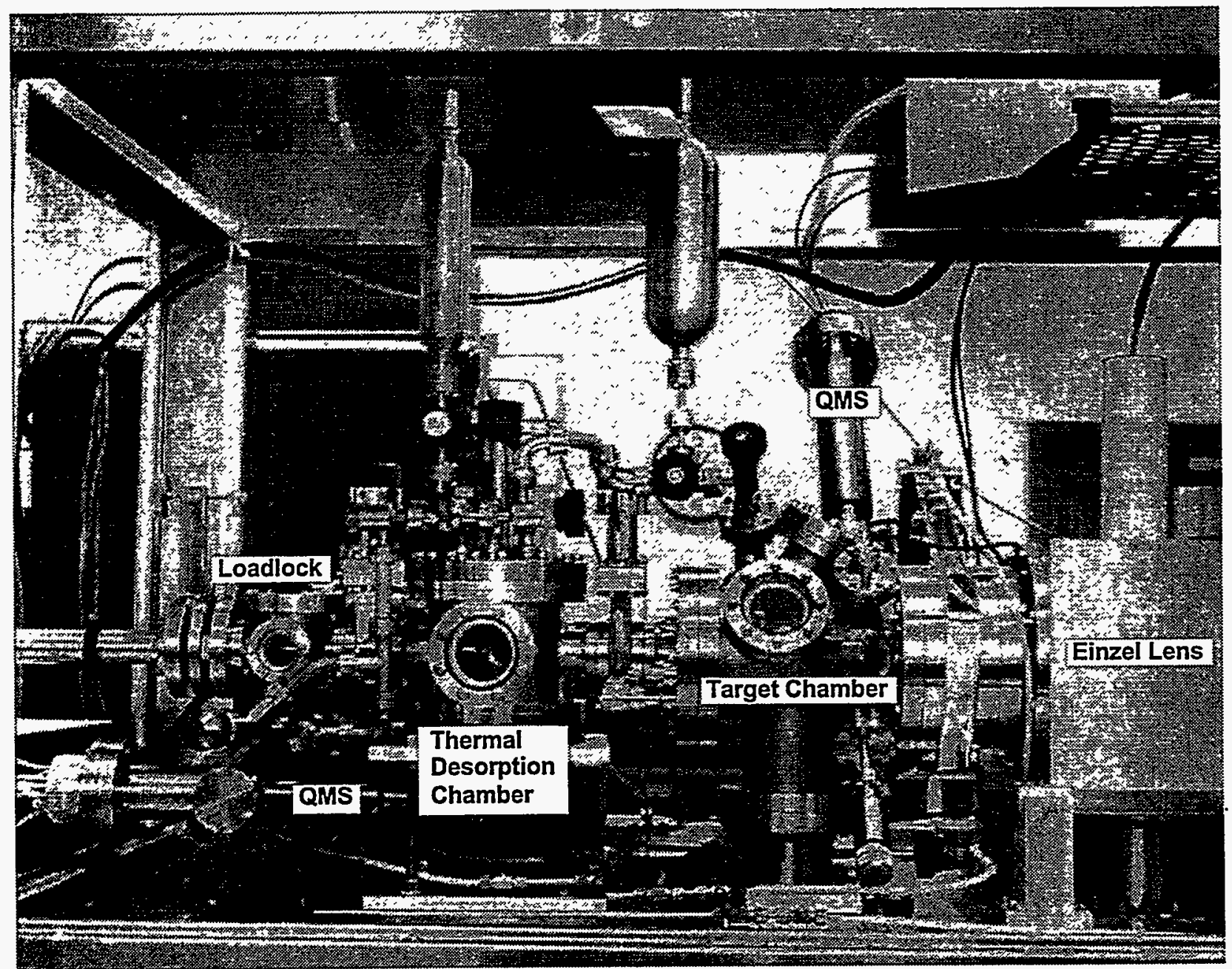

Figure 2. Photograph of the modified experimental system showing the target chamber, desorption chamber, loadlock chamber, and rotary/linear feedthrough for transfer of a sample between the system components.

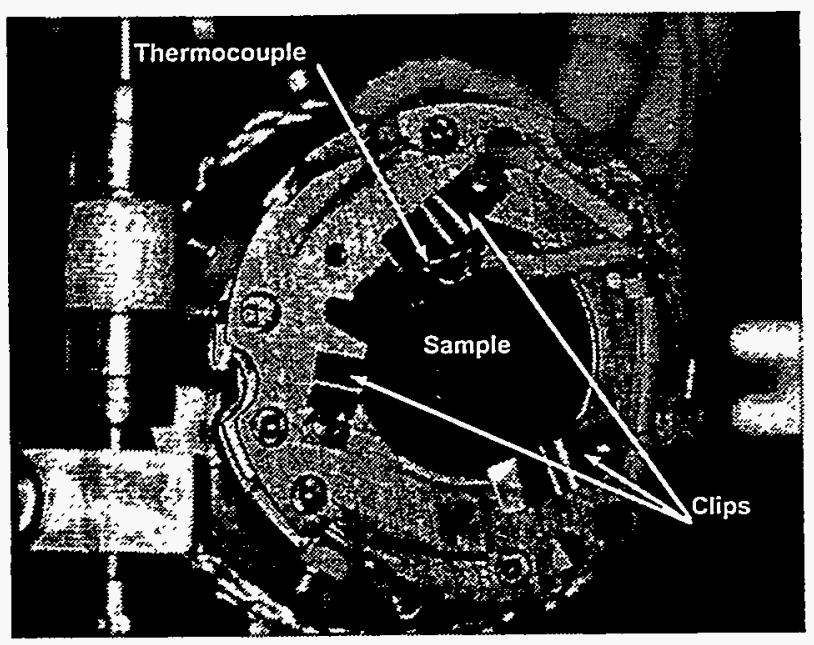

Figure 2. Sample platen with attached transferable thermocouple. result was unexpected and in contradiction to conventional theories of recombination-limited reemission from the surface of the beryllium. Usingdata from prior INEL experiments, data developed in the Russian Federation, and this TPE data, a model quantifying processes important in returning hydrogen isotopes to the plasma was developed. Usingthe TMAP4 code, this model successfully simulates results observed in the TPE experiments and others.

Tritium Source Term Analysis. The model used to successfully replicate TPE data was used to revise the estimate for tritium 
inventory in the ITER first-wall and baffle beryllium. ${ }^{3}$ That inventory estimate was only about $30 \mathrm{~g}$, which is much less than the kilogram levels that had been estimated using the classical recombination theory.

Tritium Release from Neutron Irradiated Beryllium As part of the experiments on chemical reactivity of neutron-irradiated beryllium, ${ }^{4}$ measurements were made of the tritium and helium released from the beryllium in samples annealed to various temperatures. The specimens tested in this way were fullydense Be cylinders irradiated in the EBR-II as part of the COBRA-1A2 Test. Specimens were annealed at temperatures from 450 to $1,200^{\circ} \mathrm{C}$. The annealing experiments included immersion density measurements before and after annealing and measurements of the tritium and helium gas-release behavior during specimen annealing. Based on the immersiondensity measurements, these specimens experienced significant swelling as the anneal temperature was increased, from $13 \%$ at $700^{\circ} \mathrm{C}$ to $36 \%$ at $1,200^{\circ} \mathrm{C}$. Tritium and helium release behaviors were characterized by sharp release peaks, indicative of "gas-burst-release" phenomena, for specimens annealed to $700^{\circ} \mathrm{C}$ and above. For experiments at $800^{\circ} \mathrm{C}$ and higher, helium was observed to be released concurrently with the tritium, indicating that trapped tritium resides in helium bubbles in irradiated Be. Comparable quantities of tritium were released from specimens annealed at 700 and $800^{\circ} \mathrm{C}$, and this quantity was a factor of 10 below that released during the higher temperature anneals.

\section{Future Activities}

Our work will continue to focus on providing support for the Safety and Environmental Tasks of the ITER project. A specific objective will be to conduct implantation/release experiments on samples of tungsten coated with carbon and further experiments with carbon-coated beryllium. Recent work in Euorpe ${ }^{5}$ has suggested similar mixing behavior in tungsten as was observed at the INEL for beryllium. These experiments will consist of preparation and characterization of the coated samples, annealing experiments to examine mixing, implantation to simulate the effects of plasma exposure, and thermal desorption to evaluate the amount of deuterium retained in the mixed materials and the energy with which it is retained. We will continue to provide user support for the TMAP4 code and to use that code in support of safety analyses for ITER. 


\section{References}

1. R. A. Anderl, "Initial Deuterium Implantation Thermal Desorption Experiments for Be and C-Coated Be," ITER/US/96/TE/SA-13, August 7, 1996.

2. R. A. Causey, G. R. Longhurst, and W. Harbin. "Measurement of Tritium Migration in Beryllium Using the Tritium Plasma Experiment," $12^{\text {th }}$ International Conference on Plasma Surface Interactions in Controlled Fusion Devices, Saint Raphael, France 20-24 May 1996; to be published in Journal of Nuclear Materials.

3. G. R. Longhurst, "Tritium Inventory Estimate for Metal-Faced Plasma-Facing Components in ITER," ITER/US/96/TE/SA-9 REV. 02, August 2, 1996.

4. R. A. Anderl, "Chemical Reactivity Data," ITER/US/96/TE/SA-18, October 1, 1996.

5. R. Neu et al., "Erosion and Transport of Tungsten in ASDEX Upgrade," $16^{\text {th }}$ IAEA Fusion Energy Conference, Montreal, Canada, October 7-11, 1996, proceedings to be published. 


\section{CHEMICAL REACTIVITY OF FUSION MATERIALS}

\section{Researchers: K. A. McCarthy, R. A. Anderl, M. A. Oates, R. J. Pawelko, and G. R. Smolik-INEL}

Evaluation of the safety hazards for fusion reactors includes an assessment of the failures of plasma facing component materials due to various accident scenarios. One scenario is a loss-of-coolant accident in which a water-line break injects steam into the torus vacuum vessel. The hot plasma facing material can react with the steam producing hydrogen. In this task we study the chemical reactivity of plasma facing materials.

\section{Major Accomplishments}

Our primary focus this year was to complete construction and checkout of our facility for measuring chemical reactivity of irradiated beryllium, the Steam Reactivity Measurement System (SRMS), and to test irradiated beryllium. Additionally, we measured hydrogen production from tungsten exposed to steam in the Volatilization of Activation Products Oxides Reactor (VAPOR), and analyzed data from previous copper-steam and stainless steel-steam tests in VAPOR.

Chemical Reactivity of Tungsten Alloy, Copper Alloy, and Stainless Steel. In each chemical reactivity test series, we use more than one method to measure hydrogen production. These methods include volumetric measurement, hydrogen generation based on weight gain, metallographic examination (oxide scale thickness and alloy recession), and gas chromatograph and mass spectrometer. As indicated in Table 1, each method has advantages and disadvantages. ${ }^{1}$ Measurement of hydrogen with a mass spectrometer, a gas chromatograph, and hydrogen generation based on weight gain have the lowest detection limits. The ability to detect a gas leak is also very important because air leaks can develop in a system, and volumetric methods will attribute all gas to hydrogen. By using a variety of methods, we increase confidence in our data.

We recently tested the chemical reactivity of tungsten alloy, copper alloy, and 316 stainless steel in steam. Based on our data, we developed equations to calculate hydrogen production for use in safety assessments. The parabolic rate constant we recommend for use in stainless steel-steam reaction safety calculations is:

$k_{p}\left[(m L)^{2} / \mathrm{cm}^{4} \cdot \min .\right]=2.8 \times 10^{8} \exp (-23,000 / T)(1)$

where $T$ is temperature in degrees $\mathrm{K}$. The hydrogen generation rate for copper in steam is

$$
H_{2}\left(l / m^{2} \cdot s\right)=172 \exp (-13,424 / T)
$$

and for tungsten in steam it is

$$
H_{2}\left(l / m^{2} \cdot s\right)=15,140 \exp (-16,720 / T) .
$$

In Figure 3 we compare hydrogen generation rate for stainless steel, copper alloy, and tungsten alloy to materials we have tested previously. ${ }^{2-5}$ To plot the hydrogen 
Table 1. Advantages and disadvantages of various hydrogen generation measurement techniques.

\begin{tabular}{|c|c|c|c|c|c|c|}
\hline & $\begin{array}{l}\text { Mass } \\
\text { Spectrometry } \\
\text { (MS) }\end{array}$ & $\begin{array}{c}\text { Gas } \\
\text { Chroma- } \\
\text { tography (GC) }\end{array}$ & $\begin{array}{l}\text { Volumetric } \\
\text { method } \\
(\text { Vol })\end{array}$ & $\begin{array}{l}\text { Mass gain, } \\
\text { oxygen pickup } \\
\text { (WG) }\end{array}$ & $\begin{array}{l}\text { Oxide scale } \\
\text { thickness } \\
\text { (ME) }\end{array}$ & $\begin{array}{l}\text { Alloy } \\
\text { recession } \\
(\mathrm{ME})\end{array}$ \\
\hline & & * & & & & \\
\hline Detection limit, $1 / \mathrm{m}^{2}-\mathrm{s}$ & $(2-4) \times 10^{-6}$ & $(5-8) \times 10^{-6}$ & $(1-2) \times 10^{-4}(a)$ & $5 \times 10^{-6}$ (a) & $2 \times 10^{-4}$ (a) & $2 \times 10^{-3}$ (a) \\
\hline \multicolumn{7}{|l|}{ Advantages } \\
\hline 1. Can obtain kinetic data & yes & yes & yes & no & no & no \\
\hline 2. Can identify other gases & yes & yes (limited) & no & no & no & no \\
\hline $\begin{array}{l}\text { 3. Can ensure leak tightness } \\
\text { of system }\end{array}$ & yes & yes (limited) & no & 70 & no & no \\
\hline 4. Automated sampling & yes & yes & no & no & no & no \\
\hline 5. Sampling frequency & approx. $1 \mathrm{~min}$. & approx. 5 min. & $\begin{array}{c}\text { manual } \\
\text { (can be }>M S \text { ) }\end{array}$ & end of test & end of test & end of test \\
\hline $\begin{array}{l}\text { 6. Can tolerate some } \\
\text { moisture }\end{array}$ & I0 & yes & yes & yes & yes & yes \\
\hline $\begin{array}{l}\text { 7. Can operate at various } \\
\text { steam partial pressures }\end{array}$ & yes & yes & no & yes & yes & yes \\
\hline $\begin{array}{l}\text { 8. Adaptability for long term } \\
\text { test }\end{array}$ & Towest & medium & medium & best & best & best \\
\hline $\begin{array}{l}\text { 9. Adaptability for high } \\
\text { temperatures }\end{array}$ & medium & medium & highest & medium & medium & high \\
\hline \multicolumn{7}{|l|}{ Disadvantages/limitations } \\
\hline 1. Attendance required & highest & medium & medium & Towest & Towest & lowest \\
\hline $\begin{array}{l}\text { 2. Must know or assume } \\
\text { oxidation products or } \\
\text { stoichiometry }\end{array}$ & no & no & no & yes & yes & yes \\
\hline $\begin{array}{l}\text { 3. Susceptible to oxide } \\
\text { spalling or volatilization }\end{array}$ & no & no & no & yes & yes & no \\
\hline $\begin{array}{l}\text { 4. Susceptible to } \\
\text { non uniform attack and } \\
\text { porosity/density in scale }\end{array}$ & no & no & no & no & yes & yes \\
\hline
\end{tabular}

(a) The detection limit is based upon a sample area of $0.0010 \mathrm{~m}^{2}$ and a test duration of $20 \mathrm{hr}$. Longer term tests will decrease the detection limit.

generation rate of steel we have assumed a time period of $24 \mathrm{hr}$ (an assumption of time is necessary due to the parabolic nature of the steel-steam reaction). The hydrogen generation rates of stainless steel, copper alloy, and tungsten alloy are among the lowest of all materials we have tested. These rates must be used together with accident temperature profiles to calculate total hydrogen produced during a postulated accident.

\section{SRMS Performance Tests and} Checkout. The SRMS was developed, in particular, for experiments to measure the hydrogen generation rates and tritium mobilization rates resulting from steam interaction with irradiated beryllium. ${ }^{6}$ The system comprises a flowthrough, integrated assembly with components set up in an inertgas glovebox and in a Class-A laboratory hood. We measure hydrogen generation rates in two ways: from mass-spectrometer measurements of the gas composition in the system process line and from weight gain measurements of the oxygen uptake in the samples. We measure tritium mobilization rates from measurements with an in-line ion chamber and from post-test analyses of tritium collected in ethylene glycol traps and the condensed water.

As part of our Quality Assurance (QA) plan, we have completed performance tests to check out the system. ${ }^{7}$ During these tests, we 


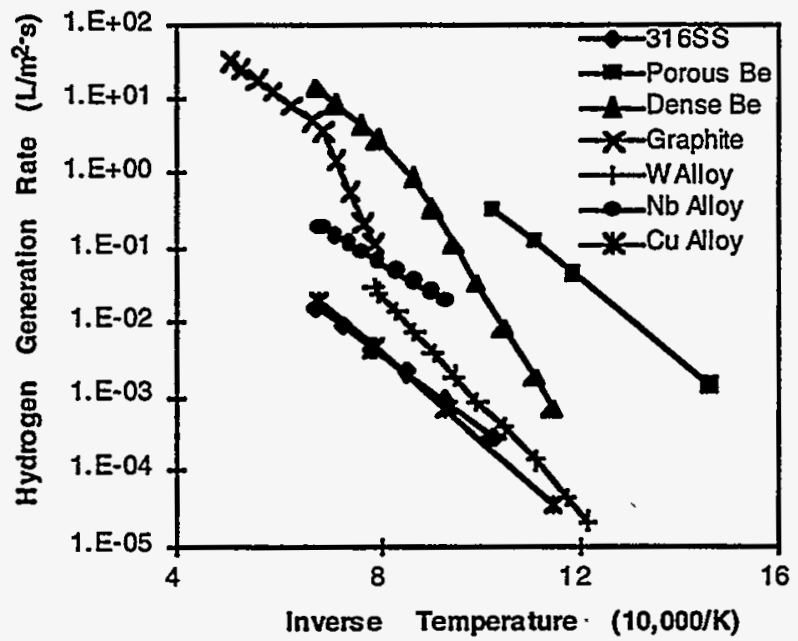

Figure 3. Comparison of hydrogen generation rates of fusion relevant materials.

determined the quadrupole mass spectrometer detection sensitivity for hydrogen and established an appropriate calibration method. The detection sensitivity of the system is about $3 \mathrm{ppm}$.

\section{Beryllium Chemical Reactivity in Steam.}

We performed three types of experiments: (1) annealing studies to measure the swelling and gas release behavior for irradiated beryllium, (2) chemical reactivity experiments for unirradiated beryllium (control samples) when exposed to steam, and (3) chemical reactivity experiments for irradiated beryllium samples exposed to steam under the same conditions as the control samples. ${ }^{8,9}$ The beryllium samples were fully dense samples fabricated with powder metallurgy techniques. Irradiation of the 0.635 and $2.032 \mathrm{~cm}$ long beryllium samples took place in Experimental Breeder Reactor II (EBR-II) as part of the COBRA$1 \mathrm{~A} 2$ test. $^{10}$ Nominal fast neutron fluences $(>0.1 \mathrm{MeV})$ were estimated to range from $5.2 \times 10^{22} \mathrm{n} / \mathrm{cm}^{2}$ to $6.7 \times 10^{22} \mathrm{n} / \mathrm{cm}^{2}$ (over an order of magnitude higher than the expected ITER fluence). The nominal irradiation temperature was $400^{\circ} \mathrm{C}$.
Measurements of the mass, density, and physical dimensions (length and diameter) were made both before and after the anneal tests. The density of the unirradiated beryllium was $1.854 \mathrm{~g} / \mathrm{cm}^{3}$ and the density of the irradiated beryllium was $1.825 \mathrm{~g} / \mathrm{cm}^{3}$, before anneal tests, indicating $1.6 \%$ swelling during the EBR-II irradiation. Key results of the immersion density measurements are summarized in Figure 4, which shows volumetric swelling for each specimen as a function of anneal temperature. Annealing at temperatures from 450 to $600^{\circ} \mathrm{C}$ resulted in little change in the swelling relative to that observed for the as-received irradiated material. However, annealing to temperatures above $600^{\circ} \mathrm{C}$ resulted in swelling, relative to unirradiated material, that ranged from $14 \%$ at $700^{\circ} \mathrm{C}$ to $56 \%$ at $1,200^{\circ} \mathrm{C}$.

Our gas analysis measurements indicated that tritium and helium gas release behavior during annealing tests was a complex function of both temperature and time at temperature.

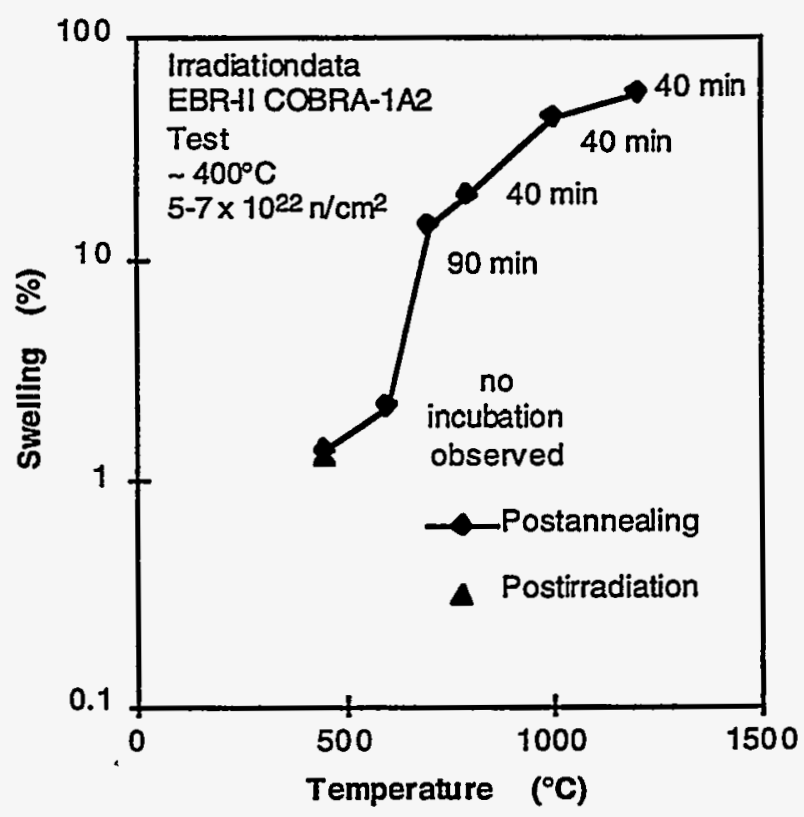

Figure 4. Swelling of irradiated beryllium as a function of anneal temperature. Incubation times are listed for each point. 
No measurable tritium and helium were observed from the specimens annealed to temperatures below $600^{\circ} \mathrm{C}$. For tests above $800^{\circ} \mathrm{C}$, bursts of helium and tritium occurred concurrently indicating that the tritium and helium reside predominantly in common bubbles in the irradiated material and are subsequently released concurrently during the thermal anneal. Figure 5 shows the gas release rates during the $1,000^{\circ} \mathrm{C}$ anneal.

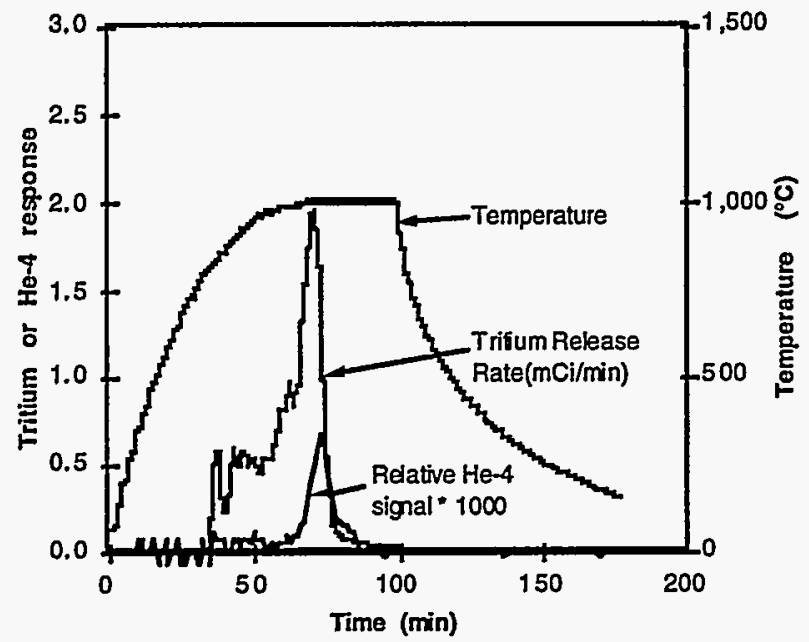

Figure 5. Tritium release rate and relative helium signal during $1,000^{\circ} \mathrm{C}$ anneal of irradiated beryllium sample.

We measured the chemical reactivity of both the irradiated and control samples exposed to steam. The control samples were tested at temperatures from 450 to $1,200^{\circ} \mathrm{C}$. The irradiated beryllium samples were tested at furnace temperatures of $450,500,600$, and $700^{\circ} \mathrm{C}$.

Based on the measured hydrogen generation rates, the chemical reactivity behavior was similar in magnitude for both the irradiated and control samples tested in steam below $600^{\circ} \mathrm{C}$. However, the irradiated sample tested at a furnace temperature of $700^{\circ} \mathrm{C}$ reacted much differently than the control sample. Hydrogen generation rates and tritium and helium mobilization measurements are shown in Figure 6. The tritium and helium releases and hydrogen generation of the sample before introduction of steam at $178 \mathrm{~min}$ were very similar to the sample annealed to $700^{\circ} \mathrm{C}$. (The gap in the data in Figure 6 was due to a temporary isolation of the sample reaction chamber with only pure argon carrier gas flowing through the ion chamber.)

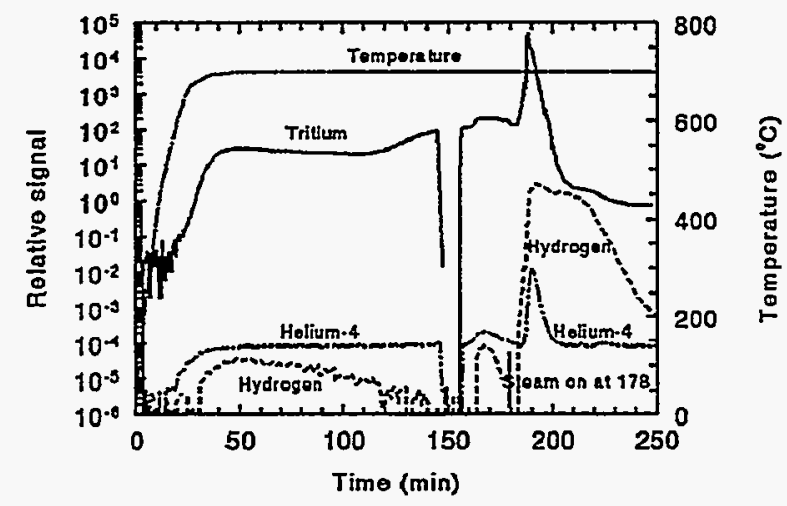

Figure 6. Tritium, helium, and hydrogen signals during $700^{\circ} \mathrm{C}$ irradiated beryllium test in steam.

Following steam introduction into the system, tritium and helium mobilization rates and hydrogen generation rates increased very rapidly, in a concurrent manner, to values that were orders of magnitude higher than those observed in the lower temperature tests on irradiated beryllium and those observed for the control sample that was tested at $700^{\circ} \mathrm{C}$. During this experiment we observed an increase in the light emission from the sample furnace interior, indicating that the specimen temperature had risen to temperatures possibly in excess of $1,000^{\circ} \mathrm{C}$.

Figure 7 compares the present data with previous work. The results are presented as average hydrogen generation rates, i.e., total quantity of hydrogen generated during steam 


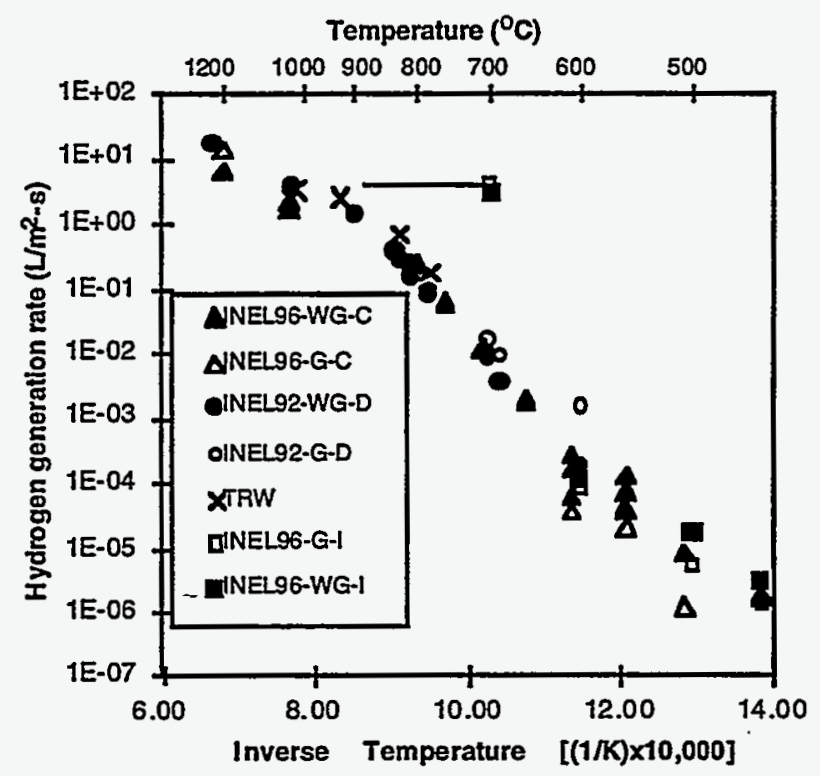

Figure 7. Comparison of hydrogen generation rates for irradiated and unirradiated beryllium cylinder samples from the present work with those reported by Smolik et al. ${ }^{11}$ and by Blumenthal and Santy. ${ }^{12}$

exposure in an experiment divided by the exposure time and the surface area of the specimen before testing. Tests designated INEL96-WG-I and INEL96-G-I are for irradiated beryllium cylinder samples from the present work while INEL96-WG-C and INEL96-G-C denote unirradiated beryllium. INEL92-WG-D and INEL92-G-D are results reported by Smolik et al., ${ }^{11}$ and those labeled TRW are by Blumenthal and Santy ${ }^{12}$. G and WG refer to analyses based on gas measurements and weight gain measurements, respectively.

We interpret the gas generation behavior for the irradiated specimen tested at $700^{\circ} \mathrm{C}$ as follows. During the heatup to $700^{\circ} \mathrm{C}$ and the conditioning at $700^{\circ} \mathrm{C}$ before initiation of steam exposure, we observed tritium release behavior that indicated swelling and evolution of a surface-connected porosity network. Based on the anneal experiments, the swelling was about $14 \%$. Consequently, when the sample was exposed to steam, the increased surface area associated with the porosity network resulted in a steam-beryllium reaction that accelerated rapidly as the exothermic heat of reaction caused the specimen temperature to rise, probably to $1,000^{\circ} \mathrm{C}$ or higher. This intense reaction caused liberation of much of the entrapped tritium and helium and further increased the reactivity until the sample was nearly consumed.

\section{Future Activities}

Further experiments are planned to provide a better understanding of chemical reactivity behavior for irradiated beryllium exposed to steam. They include (1) measurements of the effective surface areas of. irradiated specimens that show swelling from annealing, (2) measurements of chemical reactivity at temperatures below $700^{\circ} \mathrm{C}$ for the annealed, (3) irradiated samples with a characterized surface-connected porosity network, and (4) a test with a thermocoupled sample to provide the temperature history of the sample during exposure to steam. Modeling to understand the influence of the higher neutron fluence relative to ITER is also planned.

Our work will continue to support the ITER project. In addition to investigating further the chemical reactivity of irradiated beryllium., we will measure the chemical reactivity of plasma-spray beryllium exposed to air and steam. We also plan tests on tokamak dust chemical reactivity. 


\section{REFERENCES}

1. K. A. McCarthy, G. R. Smolik, K. Coates, and R. A. Anderl, Chemical Reactivity of Tungsten Alloy, Copper Alloy, and Stainless Steel Exposed to Steam, IAEA $6^{\text {th }}$ Technical Committee Meeting on Developments in Fusion Safety, Naka, Japan, October 21-25, 1996.

2. G. R. Smolik, B. J. Merrill, and R. S. Wallace, Reaction of Porous Beryllium in Steam, EGG-FSP-10346, July 1992.

3. G. R. Smolik, B. J. Merrill, S. J. Piet, and D. F. Holland, Evaluation of Graphite/Steam Interactions for ITER, EGG-FSP-9154, September 1990.

4. G. R. Smolik and K. A. McCarthy, Oxidation and Volatilization of a Niobium Alloy, EGG-FSP-10341, July 1992.

5. G. R. Smolik, B. J. Merrill, and R. S. Wallace, "Implications of Beryllium:Steam Interactions in Fusion Reactors," Journal of Nuclear Materials, 191-194, pp. 153-157, 1992.

6. R. A. Anderl, R. J. Pawelko, M. A. Oates, G. R. Smolik and K. A. McCarthy, System for Steam-Reactivity Measurements on Fusion-Relevant Materials, $12^{\text {th }}$ Topical Meeting on the Technology of Fusion Energy, Reno, Nevada, June 16-20, 1996.

7. R. A. Anderl, Performance and Scoping Test Results for Steam-Metal Chemical Reactivity System, ITER/US/96/TE/SA-17, October 17, 1996.

8. R. A. Anderl, Steam-Chemical Reactivity Experiments for Irradiated Be, ITER/US/96/TE/SA-18, October 17, 1996.

9. R. A. Anderl, R. J. Pawelko, M. A. Oates, G. R. Smolik, and K. A. McCarthy, SteamChemical Reactivity Studies for Irradiated Beryllium, IAEA 6th Technical Committee Meeting on Developments in Fusion Safety, Naka, Japan, October 21-25, 1996.

10. A. M. Ermi, Preliminary Report on the Irradiation Parameters for the EBR-II COBRA-IA2 Test, Westinghouse Hanford Company, November 1994.

11. G. R. Smolik, B. J. Merrill, and R. S. Wallace, "Implications of Beryllium Steam Interactions in Fusion Reactors," Journal of Nuclear Materials, 191-194, pp. 153-157, 1992.

12. J. L. Blumenthal and M. J. Santy, An Experimental Investigation of the Behavior of Beryllium in Simulated Launch Pad Abort Environments, TRW Systems, contract no. 82-6211, Sandia Corporation Report SCDC-65-1637, 1965. 


\title{
ACTIVATION PRODUCT MOBILIZATION AND TRANSPORT
}

\author{
Researchers: K. A. McCarthy, \\ W. J. Carmack, K. Coates, D. L. Hagrman, \\ J. E. O'Brien, and D. A. Petti, and G. R. Smolik-INEL, \\ J. P. Sharpe, M. Bourham, and J. G. Gilligan-NCSU
}

Fusion neutrons generated during the deuterium-tritium reaction will produce activation products in materials. Since activation products are an accident concern, we are examining the behavior of activation products under accident conditions. In this task we are working towards characterizing the oxidation-driven mobilization and plasmadisruption-generated activation product source terms. We are focusing on materials for the divertor, first wall, blanket, and shield, and their behavior at accident temperatures in airand steam-oxidizing environments.

\section{Major Accomplishments}

We have continued developing the database for the mobilization and transport of various elements from candidate materials for the first wall and plasma-facing components for ITER and commercial fusion reactors. We completed a series of performance tests in the scaled-up Fusion Aerosol Source Test (FAST) facility to ensure readiness to begin formal testing. We completed our first set of tests in the FAST in which we tested stainless steel in steam. During tests in the Volatilization of Activation Product Oxides Reactor (VAPOR) facility where we exposed tungsten alloy to air and to steam, we were able to measure statistically significant mobilization rates at temperatures as low as $400^{\circ} \mathrm{C}$. We began experiments in the Surface Interaction
Experiment at North Carolina State (SIRENS) disruption simulator to characterize the material mobilized during a plasma disruption. Our modeling efforts included a parametric study to determine the aerosol transport behavior of beryllium dust through ITER penetrations under representative accident conditions.

Activation Product Mobilization Task. During this fiscal year, the mobilization task focused on three areas: (1) performance tests in the FAST facility to ensure readiness for formal testing, (2) mobilization of stainless steel in steam, and (3) tungsten alloy mobilization in air and steam.

As part of our Quality Assurance program, the FAST facility was tested in five separate full performance tests. ${ }^{1}$ These tests involved system checkout and comparison with results from our VAPOR facility. Figure 8 shows the time-temperature history for one of the shakedown tests. This is an example of the information that was generated during performance tests to ensure the facility was ready for formal testing.

After successful completion of performance testing, we carried out a series of 316 stainless steel mobilization experiments in steam. ${ }^{2,3}$ The primary purpose of these experiments was to reduce detection limits 


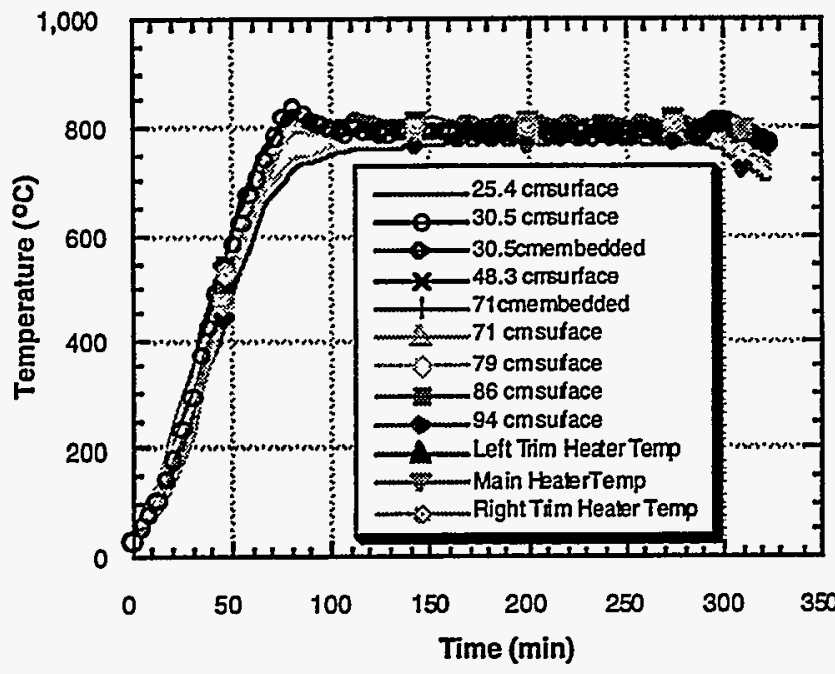

Figure 8. Time-temperature history of $800^{\circ} \mathrm{C}$ test in steam, inlcuding surface and embedded thermocouples.

relative to previous measurements in VAPOR, concentrating on temperatures below $800^{\circ} \mathrm{C} .^{4}$ The data from the tests show the following: (1) there is a progressive increase of measured mass flux for $\mathrm{Fe}, \mathrm{Mo}, \mathrm{Mn}, \mathrm{Zn}$, and $\mathrm{Cr}$ with test temperature between 500 and $800^{\circ} \mathrm{C}$, (2) mass flux measurements from FAST and VAPOR agree within a factor of three for elements with volatile oxide or hydroxide species such as $\mathrm{Cr}$ and Mo, (3) mass fluxes of elements associated with oxide spalling in VAPOR, mainly $\mathrm{Fe}$ and $\mathrm{Mn}$, were up to a factor of 90 lower in the FAST test than in the VAPOR test at $800^{\circ} \mathrm{C}$, and (4) detection limits in FAST were lower than those measured in VAPOR due to the larger surface area of the source in FAST tests. Figure 9 shows a comparison of selected data from FAST and VAPOR steam exposure tests at $800^{\circ} \mathrm{C}$.

During our tungsten-air, tungsten-steam mobilization tests series, much of our effort was directed toward reducing detection limits. We have improved our analytical processes by lowering detection limits with inductively coupled plasma-atomic emission spectroscopy and with inductively coupled plasma mass spectroscopy. We have also improved our methods that account for inherent chemical contributions from test components and filters used to collect mobilized species. As a result, we were able to make statistically significant measurements at lower temperatures than was possible before, in the $400-600^{\circ} \mathrm{C}$ temperature range. ${ }^{5-7}$ As accident analyses become more sophisticated and designers work towards designs that decrease accident temperatures, the $400-600^{\circ} \mathrm{C}$ temperature range becomes very important.

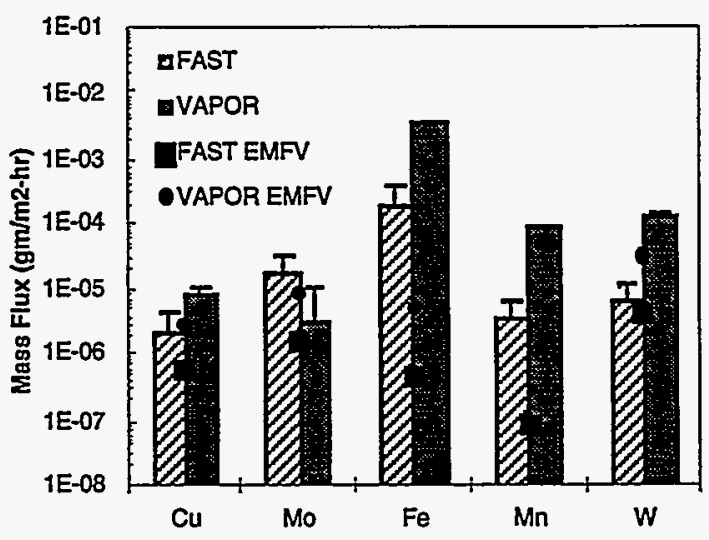

Figure 9. Comparison of selected data from FAST and VAPOR steam exposure tests at $800^{\circ} \mathrm{C}$.

The detection limits for mass fluxes of cobalt, tungsten, rhenium, and tantalum were reduced three orders of magnitude during air tests compared with those achieved in our earlier study. ${ }^{8}$ Copper and tungsten detection limits were over an order of magnitude lower than previous tests. Figure 10 shows the early dose (stability class $B, 1-\mathrm{m} / \mathrm{s}$ wind, $1-\mathrm{km}$ site boundary, elevated release, no rain) due to air exposure per hour at temperature, per square meter exposed surface area. The dose is due 


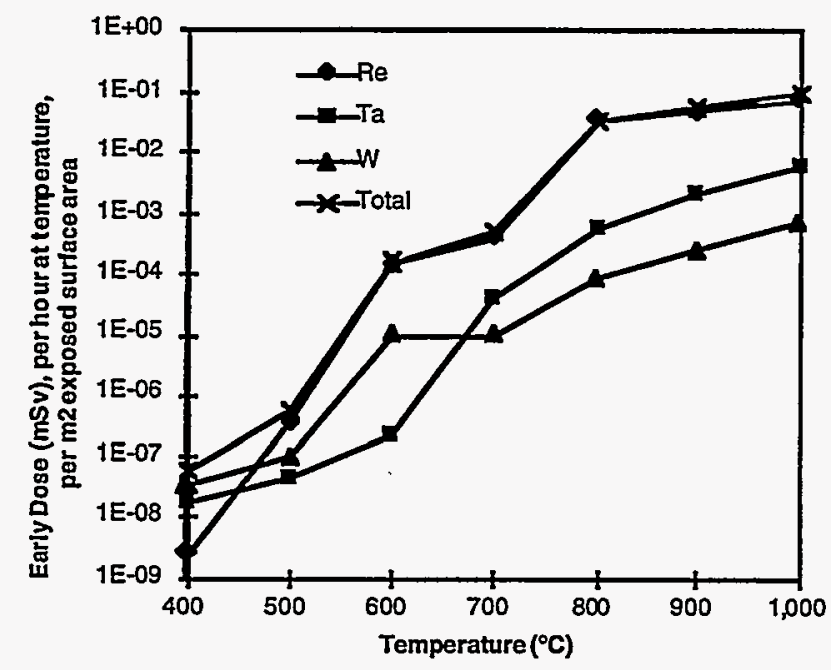

Figure 10. Early dose (elevated release, stability class $B, 1-\mathrm{m} / \mathrm{s}$ windspeed, $1-\mathrm{km}$ site boundary) from tungsten first wall coating exposed to air per hour at temperature, per $\mathrm{m}^{2}$ surface area, no credit for any radioactivity confinement.

primarily to rhenium, tantalum, and tungsten activation products.

Detection limits in tungsten steam tests were similarly reduced. Detection limits for cobalt, rhenium, and tantalum were two orders of magnitude lower than previous studies, and were over one order of magnitude lower for copper and tungsten. Figure 11 shows the early dose due to steam exposure (stability class $B, 1-\mathrm{m} / \mathrm{s}$ wind, $1-\mathrm{km}$ site boundary, elevated release, no rain) per hour at temperature, per $\mathrm{m}^{2}$ exposed surface area. The dose is due primarily to rhenium, tantalum, and tungsten activation products.

Aerosol Transport Task. The primary work in this area was a parametric scoping study using the AEROFLW code to examine aerosol transport behavior of tokamak dust through ITER penetrations (e.g., plasma heating ducts) under representative conditions for ITER confinement bypass events. ${ }^{9}$ Very

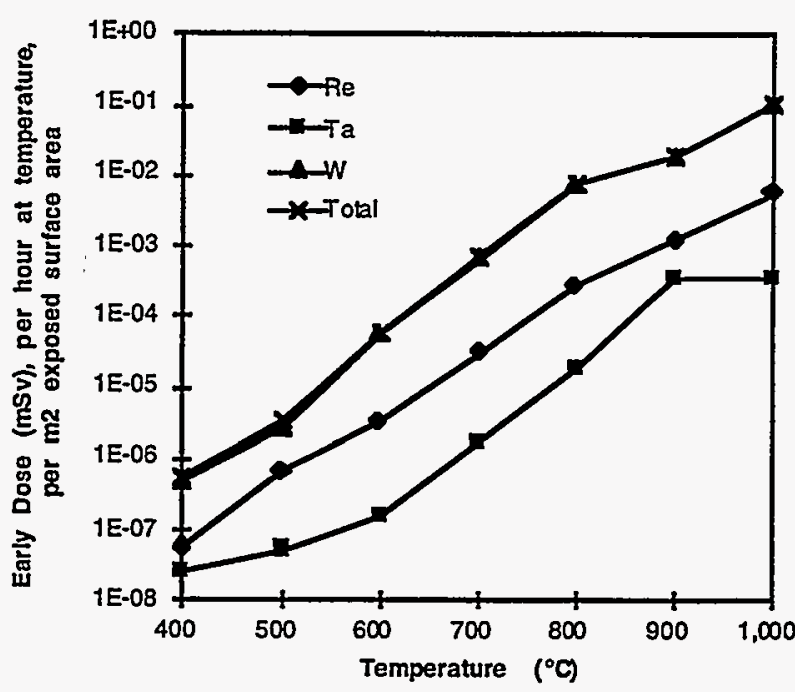

Figure 11. Early dose (elevated release, stability class $B, 1-\mathrm{m} / \mathrm{s}$ windspeed, $1-\mathrm{km}$ site boundary) from tungsten first wall coating exposed to steam per hour at temperature, per $\mathrm{m}^{2}$ surface area, no credit for any radioactivity confinement.

large particles $(>10 \mu \mathrm{m})$ generally will not make it out of the facility. For the more easily transportable particles between 1 and $5 \mu \mathrm{m}$, the results are sensitive to the details of the penetration geometry and thermal hydraulics. Aerosol leakage is largest for the very small particles $(0.1-0.5 \mu \mathrm{m})$ since inertial and gravitational effects are not very important for these sizes. Aerosol deposition from turbulent flow, inertial impaction at bends, and gravitational settling all reduce the aerosol leakage to the environment if ITER penetrations fail during an accident scenario. The most important parameters in determining the magnitude of the reduction are:

- Aerosol particle size

- Surface roughness of penetration duct

- Time of the transient

- Leak rate of building where penetration occurs.

However, aerosol agglomeration in the building and vacuum vessel, which was not considered 
in the AEROFLW calculations, will cause the particle size to increase and the overall leakage to decrease as inertial deposition effects begin to become important. Water condensation onto particles would have the same effect. Such coupled phenomena can be evaluated using the MELCOR code as has been done for the ITER NSSR-1 (see section on fusion safety code development).

\section{Aerosol Mobilization from Disruptions.}

During a plasma disruption, activated plasmafacing component material can be removed from the surface by vaporization. This vaporized mass will condense on surrounding walls and/or nucleate into an aerosol, depending on the physical conditions in the vacuum vessel following the disruption. The purpose of this task is to characterize and quantify the material mobilized during a disruption.

We are using the SIRENS electrothermal plasma gun at North Carolina State University (see Figure 12) to perform these studies. SIRENS is an appropriate facility to study aerosol mobilization in disruption-like conditions because of the reasonable similarity of primary ITER disruption parameters such as disruption energy, energy pulse duration, disruption power flux to walls, and expansion volume ratio. ${ }^{10}$

We have completed two proof-of-principle tests. Each test used a copper source section liner as the test material, and collection buttons were distributed in the expansion chamber. Figure 13 shows the particle size distribution for one of the tests. The counting technique did not resolve particles smaller than $1 \mu \mathrm{m}$, in future tests the counting technique will be improved to account for these small particles.

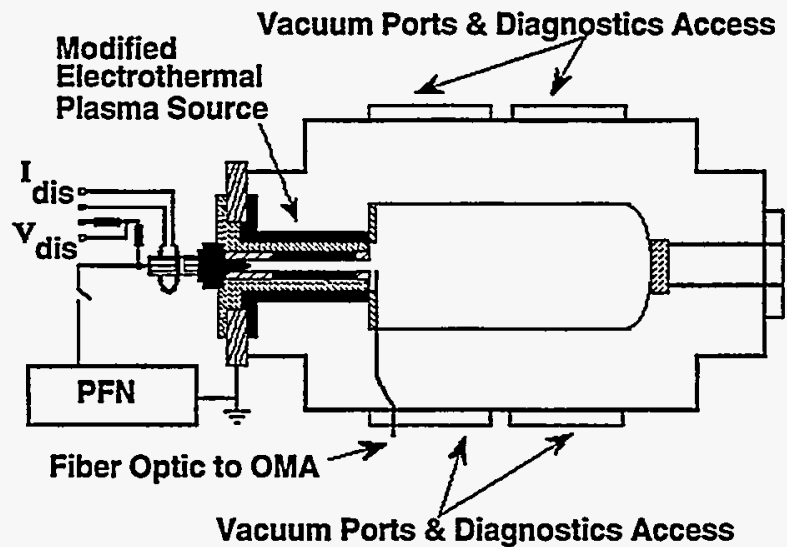

Figure 12. Schematic of the SIRENS facility modified for aerosol tests, showing source section and expansion chamber.

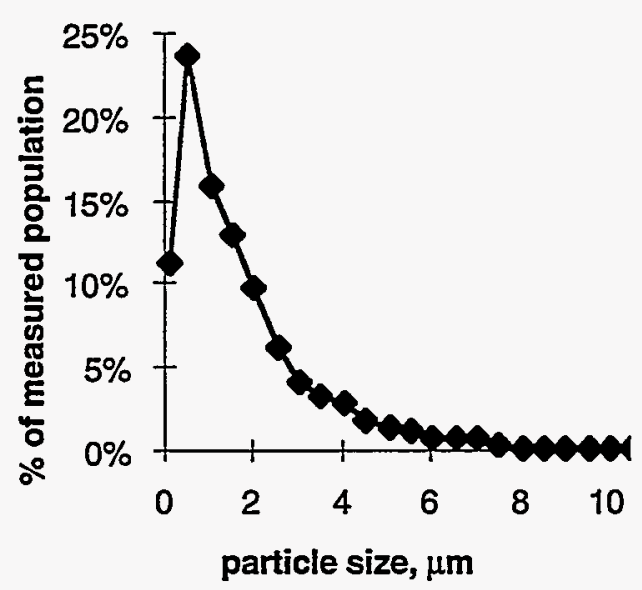

Figure 13. Particle size histogram for proofof-principle test with copper source.

\section{Future Activities}

Our work will continue to support the ITER project. Copper will be tested in air and steam in the FAST facility. Mobilization of plasma-sprayed beryllium will be measured in VAPOR. We will continue characterization of plasma-disruption induced aerosols. A new area of emphasis for us will be characterization of tokamak dust. We will analyze dust samples collected in DII-D and TFTR. 


\section{References}

1. W. J. Carmack, G. R. Smolik, and J. E. O'Brien, Performance Test Results of the FAST Apparatus, ITER/US/96/TE/SA-08, June 1996.

2. W. J. Carmack and G. R. Smolik, Fusion Aerosol Source Test (FAST) Steam Exposure of 316 Stainless Steel, ITER/US/96/TE/SA-20, October 1996.

3. W. J. Carmack, G. R. Smolik, and K. A. McCarthy, Mobilization of 316 Stainless Steel From 500 to $800^{\circ} \mathrm{C}$ in Steam, presented at the IAEA $6^{\text {th }}$ Technical Committee Meeting on Developments in Fusion Safety, Naka, Japan, October 21-25, 1996.

4. K. A. McCarthy, G. R. Smolik, and S. L. Harms, A Summary and Assessment of Oxidation Driven Volatility Experiments at the INEL and their Application to Fusion Reactor Safety Assessments, EGG-FSP-11193, September 1994.

5. G. R. Smolik and K. Coates, Mobilization From Oxidation of a Tungsten Alloy in Air, ITER/US/96/TE/SA-2 (Rev. 1), September 26, 1996.

6. K. A. McCarthy and G. R. Smolik, Dose Due to Mobilization of Tungsten Activation Products in Air, 19 ${ }^{\text {th }}$ Symposium on Fusion Technology, Lisbon, Portugal, September 16-20, 1996.

7. G. R. Smolik and K. Coates, Mobilization From Oxidation of a Tungsten Alloy in Steam, ITER/US/96/TE-SA-21, November 11, 1996.

8. G. R. Smolik, S. J. Piet, and R. M. Neilson, Jr., "Predictions of Radioactive Tungsten Release for Hypothetical ITER," Fusion Technology, 19, pp. 1398-1402, May 1991.

9. D. A. Petti, Aerosol Transport Behavior in ITER Penetrations: A Sensitivity Study, ITER/US/95/TE/SA-34, December 8, 1995.

10. J. P. Sharpe, Progress Report on Aerosol Mobilization From Disruptions, ITER/US/96/TE/SA-11, July 29, 1996. 


\title{
FUSION SAFETY COMPUTER CODE DEVELOPMENT
}

\author{
Researchers: B. J. Merrill, K. E. Carlson, M. J. Gaeta, D. L. Hagrman, \\ D. A. Petti, S. T. Polkinghorne -INEL \\ S. C. Jardin-Princeton Plasma Physics Laboratory
}

Fusion experiments, and eventually fusion power plants, will generate or contain radioactive material in the form of activation products and tritium. These facilities will have a variety of energy sources that can mobilize these materials in several different forms during loss-of-vacuum-accidents (LOVAs), lossof-cooling-accidents (LOCAs), or plasma disruptions. These energy sources include: fusion neutron and particle heat, structure decay heat, plasma-stored thermal and magnetic energy, coolant pressurization, chemical reactions, and hydrogen production and possible combustion. The mobilized forms radioactive material can take are: (1) dust resulting from plasma-facing-component (PFC) erosion during normal operation, which can contain tritium or activation products, (2) aerosols resulting from structure surface oxidation, (3) aerosols resulting from $\mathrm{PFC}$ erosion during plasma disruptions, (4) isotopic exchange of tritium from PFCs with spilt coolants, and (5) cooling system corrosion products. The extent to which these materials can be confined, and thereby the amount of radioactive material released to the environment reduced, will depend on the degree to which the integrity of confinement barriers can be maintained during LOVAs, LOCAs, and plasma disruptions.

The objective of this task is to obtain, modify, or develop safety computer codes capable of analyzing these events. Several codes are now being pursued. These codes are: ATHENA, CHEMCON, DSTAR, and
MELCOR. The following paragraphs describe our progress during FY-97.

\section{Major Accomplishments}

ATHENA. Fusion reactors will require several interacting coolant systems to remove heat from the first wall, blanket, limiter or divertor, and cryogenic superconducting magnets. Different cooling fluids will be used in each of the systems. These separate systems will be interconnected by heat exchangers. To understand and analyze the interactions among these cooling systems, the Idaho National Engineering Laboratory is developing a transient analysis code called ATHENA ${ }^{1}$ to simulate both routine and accident conditions.

ATHENA is a nonequilibrium model of the two-phase fluid conservation equations. The ATHENA code is based on the RELAP5/MOD3 code ${ }^{2}$ and is being developed by modifying RELAP5 to include a range of fluids and new constitutive models. ATHENA also includes many generic component models from which general systems can be modeled, such as: pumps, valves, pipes, heat structures, electric heaters, jet pumps, turbines, separators, and control system components. In addition, special process models are included for effects such as form losses, flow at abrupt area changes, branches, choked flow, magnetohydrodynamic effects, solute tracking, and noncondensable gases. 
This fiscal year, an ATHENA input model for the vacuum vessel heat transport system of the International Thermo-nuclear Engineering Reactor (ITER) design was developed as part of this task, ${ }^{3}$ and transmitted to the Safety Group of the ITER Joint Central Team (JCT) for accident analyses in support of the Non-Site Specific Safety Report (NSSR-1). ${ }^{4}$ This model, which represents either of two independent cooling systems, simulates one-half of the vacuum vessel (every other sector), the pressurizer, the air-cooled heat exchanger, the pump, the flow control valve, and the interconnecting piping. A simple control system is used to establish the initial vacuum vessel flow rate, pressure, and inlet and outlet temperatures This model is intended primarily for natural circulation analysis, although it can easily be modified for LOCA analysis. Two checkout calculations were performed at the INEL (steady-state and transient loss-of-flow) to ensure that the model functioned as intended.

DSTAR. Tokamak plasma disruptions can produce severe structural damage and potentially mobilize tritium, activated dust, and structure activation products. For example, "hard" plasma disruptions rapidly release the plasma magnetic and thermal energy, creating significant protective tile erosion, and induced structural forces. In addition, high loop voltages occur that can generate high energy runaway electrons. If the generated runaway current is large, these electrons could cause significant first wall and blanket damage when lost from the plasma.

With these issues in mind, the focus of this task has been on developing and validating comprehensive models to ensure that proposed reactor designs can safely withstand off-normal plasma events. These models are being added to the Tokamak Simulation Code (TSC), ${ }^{5}$ a tokamak free-boundary plasma physics code under development at the Princeton Plasma Physics Laboratory (PPPL), with the resulting code being called DSTAR. ${ }^{6}$ In adopting this approach, we self-consistently deal with plasma disruptions by accounting for plasma motion, plasma/impurity transport, and induced structural eddy currents.

This year, a "killer pellet" ablation model was added to the DSTAR code. These pellets contain high $\mathrm{Z}$ impurities such as neon or krypton, and are being proposed as part of a fast safety plasma shutdown system for ITER. Results from this model compare well with data from the Tokamak Fusion Test Reactor (TFTR) at the Princeton Plasma Physics Laboratory, and suggest that krypton doped hydrogen pellets look promising as a means for mitigating severe vertical displacement events (VDEs) in ITER.

MELCOR. ITER will contain radioactive material in the form of activation products and tritium. ITER will have a variety of energy sources that can mobilize these materials during hypothetical accidents, such as a LOCA. MELCOR allows for a nonequilibrium treatment of both the liquid and vapor phases of water, and the transport of both phases along with aerosols between computational volumes of the system being modeled. 7

Two major code development efforts were completed for MELCOR this fiscal year. First, heat transfer correlations were added to the MELCOR heat transfer package for nucleate boiling of water flowing in heated pipes. The boiling correlations added to MELCOR were the $\mathrm{Chen}^{8}$ equations for 
nucleate boiling heat transfer and the Biasi ${ }^{9}$ correlation for critical heat flux. These correlations supplement those in MELCOR for pool (i.e., nonflow) nucleate boiling. Second, a version of MELCOR was developed that substitutes air for water as the working fluid. This modification included an equation of state for air, and gas/liquid/solid thermal properties at temperatures as low as cryogenic helium temperatures. The verification and validation of these two development efforts will be documented in the immediate future. ${ }^{10}$

Accidents involving the ingress of air or water into the cryostat of the ITER tokamak design were analyzed with the MELCOR code for the ITER NSSR-1. The cryostat is the secondary radioactive material confinement barrier of the ITER device. To investigate the robustness of this confinement barrier, unlikely (frequency $1 \times 10^{-2} / \mathrm{yr}$ to $1 \times 10^{-4} / \mathrm{yr}$ ) and extremely unlikely (frequency between $1 \times 10^{-4}$ to $1 \times 10-6 / y r$ ) events that result in the ingress of air and water into the cryostat were examined.

The air ingress accidents are the result of a postulated breach of the cryostat boundary, such as a metal bellows failure at a cryostat penetration. The consequences are increased heat and weight to magnets as a result of air condensation on the magnets and a partial vacuum developing in adjoining rooms of the ITER facility. Pressures from this analysis are shown in Figure 14. The cryostat pressure increased only slightly during the first $3000 \mathrm{~s}$ of this accident. The rate of pressurization is being limited by the magnets condensing the air that enters through the cryostat breach. After $3000 \mathrm{~s}$, the pressure in the cryostat rises to a maximum value of
$0.105 \mathrm{MPa}$ by $6.7 \mathrm{hr}$. The pressure of an adjoining room to the cryostat by way of this breach (equatorial pit) drops to a minimum pressure of $0.084 \mathrm{MPa}$ by $2.6 \mathrm{hr}$. This pressure then returns to atmospheric values by $5.6 \mathrm{hr}$. While the cryostat pressure is well below the design limit of $0.2 \mathrm{MPa}$, the equatorial pit pressure did drop below the design limit pressure of $0.09 \mathrm{MPa}$. The condensed air mass and increased heat loads for the magnets are not a safety concern for the magnets, but the partial vacuum in the adjoining room must be designed for.

It was also postulated that a toroidal field (TF) magnet could experience an electrical insulation fault that results in an intense electrical arc. It is assumed that sufficient energy is available to melt a helium cooling line from a TF coil, a Primary Heat Transport System (PHTS) guard pipe, and a PHTS coolant pipe within the guard pipe. This accident discharges PHTS water, TF coil helium, and the activated corrosion products

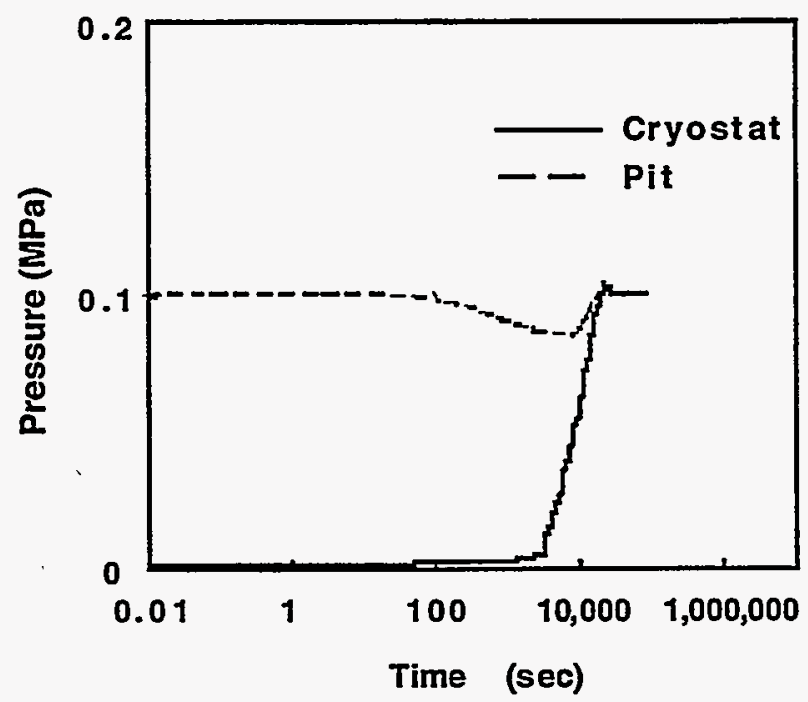

Figure 14. Cryostat and divertor pit pressures for the cryostat air ingress accident scenario. 
and tritiated water (HTO) in the PHTS water into the cryostat. The cryostat pressure in Figure 15 reaches a maximum value of $0.17 \mathrm{MPa}$ in $180 \mathrm{~s}$, then drops as the helium leak subsides. This pressure reaches a second maximum of $0.16 \mathrm{MPa}$ by $3.8 \mathrm{hr}$, due to the heatup of structures in the cryostat through heat transfer with the environment, and is limited to $0.16 \mathrm{MPa}$ by the emergency helium pumping system of the cryostat. By $29 \cdot \mathrm{hr}$ subatmospheric pressures are obtained in the cryostat. These pressures are below the design limit pressure for the cryostat of $0.2 \mathrm{MPa}$ for this accident. As water enters the cryostat it condenses on the TF and PF coil structures, causing these structures to rapidly heat up, note Figure 16 . The TF coil case, poloidal field (PF) coil, and thermal shield reach temperatures of 140,210 , and $255 \mathrm{~K}$ in $3 \mathrm{hr}$, respectively. However, the condensed water mass and increased heat loads for the magnets are not a safety concern, and the HTO and corrosion product releases

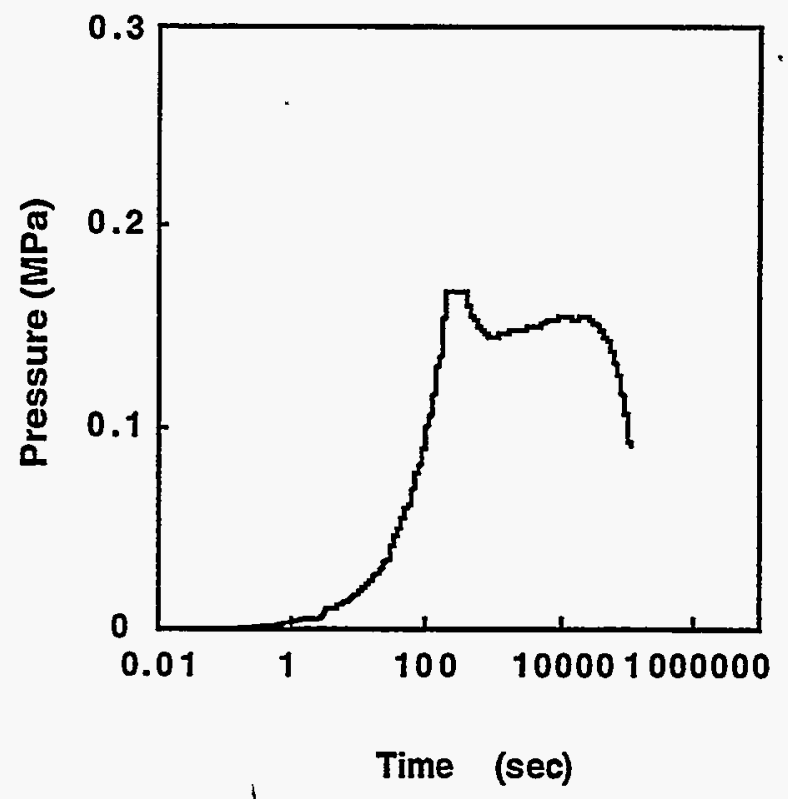

Figure 15. Cryostat pressure for the cryostat water and helium ingress accident.

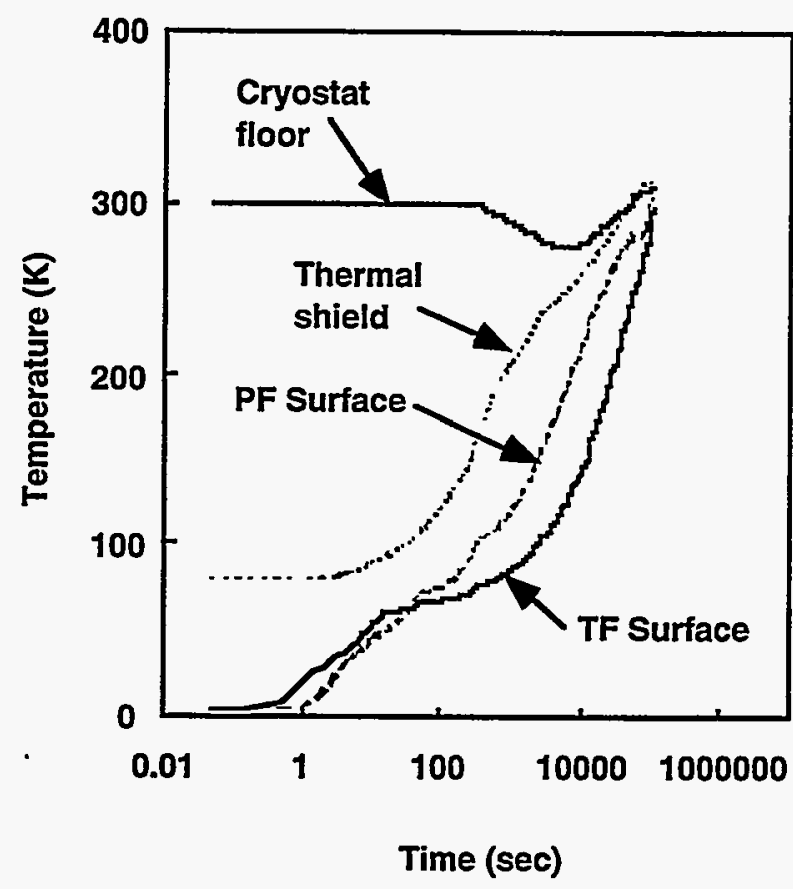

Figure 16. Cryostat structure temperatures for the cryostat water and helium ingress accident scenario.

are well within the ITER release limits.

To examine the robustness of the ITER primary confinement barrier (vacuum vessel plus penetrations), small, medium, and large in-vessel LOCAs associated with the wall and baffle cooling systems of the ITER design were also analyzed with MELCOR for the ITER NSSR-1. ${ }^{11}$ A range of break sizes from one first wall (FW) tube break $\left(1.57 \times 10^{-4} \mathrm{~m}^{2}\right)$ to damage of all in-vessel components $\left(0.6-\mathrm{m}^{2}\right.$ break) has been chosen to envelope all types of LOCAs in each of the three ITER event categories: likely events, unlikely events, and extremely unlikely events. In addition, we have studied in-vessel pipe breaks in combination with bypass of the two ITER confinement barriers through a generic penetration.

A postulated likely accident is a double ended pipe rupture of an in-vessel first 
wall/inboard baffle pipe during a plasma burn $\left(1.57 \times 10^{-4} \mathrm{~m}^{2}\right)$. The single pipe break could be the result of a crack in the pipe from a flaw, from thermal and mechanical overstress, or from erosion-induced wall thinning.

A postulated unlikely event is an intense plasma disruption that causes moderate damage to coolant tubes in the in-vessel cooling systems $\left(0.1 \mathrm{~m}^{2}\right.$ total area). This event envelopes FW damage that could be produced by plasma induced transients such as edge localized modes, VDEs, runaway electrons generated during plasma disruptions, and multifaceted asymmetric radiation from the edge of the plasma that could occur as a consequence of ITER operations.

A postulated extremely unlikely event is a VDE where the plasma drops downward, contacting both the inner and outer FW in the lower part of the machine, causing FW pipe damage during a plasma burn. A large number of FW modules around the circumference of the machine are postulated to be damaged in this event resulting in a total break area of 0.6 $\mathrm{m}^{2}$. A second extremely unlikely accident is a double ended rupture of a single in-vessel FW tube during a plasma burn (1.57E-04 $\mathrm{m}^{2}$ total area). As the pressure builds in the vacuum vessel, a vacuum vessel penetration line $(0.02$ $\mathrm{m}^{2}$ cross-sectional area) into an adjoining room designated as the "generic bypass room (GBR)" is assumed to fail as a result of the $0.1-\mathrm{MPa}$ steam pressure in the vacuum vessel.

In the first three in-vessel LOCA scenarios examined, the pressure response of the system is determined by the magnitude of the break and the timing of the actuation of the vacuum vessel pressure suppression system. Table 2 summarizes the vacuum vessel pressure results for the three cases examined. As expected, smaller breaks generally take longer to pressurize the vacuum vessel and actuate the suppression system than larger breaks. Peak pressures for the smaller breaks were less than for the larger breaks.

Table 2. Summary of ITER In-vessel LOCA Pressurization Results.

\begin{tabular}{|c|c|c|c|}
\hline \multicolumn{4}{|c|}{ LOCA Case } \\
\hline $\begin{array}{c}\text { One FW } \\
\text { pipe break }\end{array}$ & $\begin{array}{l}10 \mathrm{FW} \\
\text { pipe } \\
\text { breaks }\end{array}$ & $\begin{array}{c}\text { In-vessel } \\
\text { coolant } \\
\text { leak as a } \\
\text { result of } \\
\text { a plasma } \\
\text { transient }\end{array}$ & $\begin{array}{l}\text { Multiple } \\
\text { FW pipe } \\
\text { breaks }\end{array}$ \\
\hline \multicolumn{4}{|c|}{ ITER Event Category } \\
\hline II & II & III & IV \\
\hline \multicolumn{4}{|c|}{ In-vessel Break Size $\left(m^{2}\right)$} \\
\hline $1.57 \times 10^{-4}$ & $1.57 \times 10$ & 0.1 & 0.6 \\
\hline \multicolumn{4}{|c|}{ Peak VV Pressure (MPa) } \\
\hline 0.21 & 0.21 & 0.225 & 0.42 \\
\hline \multicolumn{4}{|c|}{ Time of suppression system actuation (s) } \\
\hline & 100 & 6.7 & \\
\hline
\end{tabular}

The opening of the rupture disks to the ITER pressure suppression system is the dominant factor in the transport of dust, corrosion products, and HTO in these scenarios. Almost all of the radioactivity in these cases ends up in the liquid in the suppression pool. In all cases, releases were well below the appropriate ITER release limits. $^{11}$

Figure 17 is a plot of the airborne mass of dust, corrosion products, and tritium in the GBR as a function of time for the final accident scenario. The mass of dust, corrosion products, and tritium increase with and $3000 \mathrm{~s}$. The maximum airborne masses in the GBR are: $120 \mathrm{~g}$ of dust, $17 \mathrm{~g}$ of corrosion time, with a broad maximum between 1000 


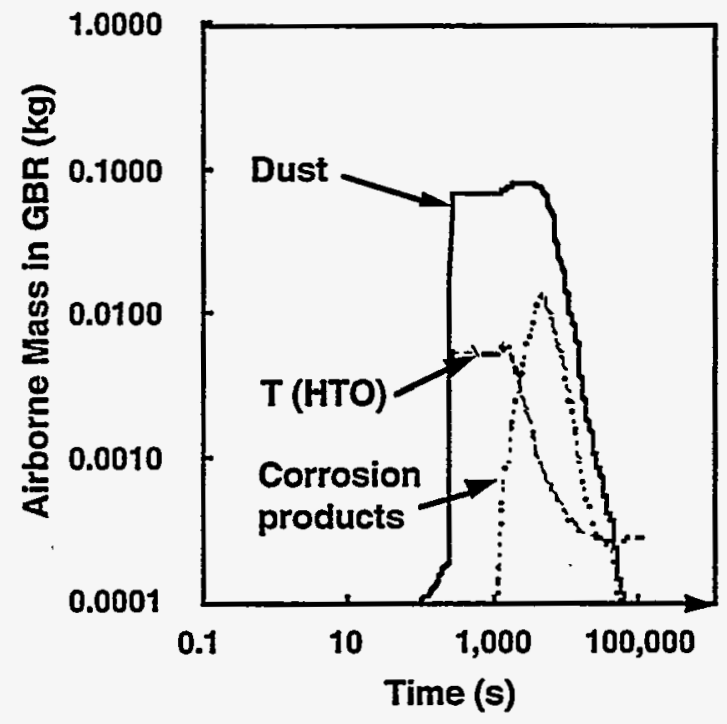

Figure 17. Airborne mass of dust, corrosion products, and tritium in generic bypass room (GBR) for in-vessel pipe break and vacuum vessel penetration bypass.

and 3,000 s. The maximum airborne masses in the GBR are: $120 \mathrm{~g}$ of dust, $17 \mathrm{~g}$ of corrosion products, and $7 \mathrm{~g}$ of $\mathrm{T}$. Once pressure stabilization occurs in the system at $2.2 \mathrm{hr}$, the dust and corrosion products in the GBR decrease with time due to steam condensation onto the particulates, agglomeration and subsequent settling, and leakage from the GBR. The tritium concentration in the GBR decreases more gradually due to steam condensation and leakage from the GBR and levels off to a value of $\sim 0.4 \mathrm{~g}$ at $10,000 \mathrm{~s}$. Releases from the GBR to the environment were within ITER release limits.

\section{Future Activities}

During the upcoming fiscal year, modifications to MELCOR will be made to better model the behavior of aerosols present during hypothetical thermal-hydraulic accidents such as LOCAs and LOFAs. We will also perform calculations for the second ITER Non-Site Specific Safety Report. 


\section{References}

1. K. E. Carlson, P. A. Roth, and V. H. Ransom, ATHENA Code Manual, Volume 1 and 2, EGG-RTH-7397, September 1986.

2. C. M. Allison, et al., RELAP5/MOD3 Code Manual, Volumes 1, 2, 3, and 4, NUREG/CR-5535, EGG-2596, June 1990.

3. S. T. Polkinghorne and K. E. Carlson, "A Preliminary ATHENA Model of the ITER Vacuum Vessel Heat Transport System," EDF No. ITER/US/96/TE/SA-07, May 9, 1996.

4. H-W. Bartels, editor, Accident Analysis Specifications for NSSR-I (AAS), Version 1.2, S 81 RE 4 96-03-12 W1.1, SEHD 8.1.C-1, ITER Program, May 31, 1996.

5. S. C. Jardin, N. Pomphrey, and J. Delucia, "Dynamic Modeling of Transport and Positional Control of Tokamaks," Journal of Computational Physics, 66, p. 481, 1986.

6. B. J. Merrill and S. C. Jardin, "DSTAR: A Comprehensive Tokamak Resistive Disruption Model For Vacuum Vessel Components," Fusion Engineering and Design, 5, pp. 235-249, 1987.

7. R. M. Summers, R. K. Cole, Jr., E. A. Boucheron, M. K. Carmel, S. E. Dingman, J. E. Kelly, MELCOR 1.8.0: A Computer Code for Nuclear Reactor Severe Accident Source Term and Risk Assessment Analyses, NUREG/CR-5531 and SAND90-0364, January 1991.

8. J. C. Chen, "A Correlation for Boiling Heat Transfer to Saturated Fluids in Convective Flow," ASME Paper, no. 63-HT-34.

9. L. Biasi, et al., "Studies on Burnout," Part 3, Energia Nucleare, 14, (9), pp. 530-536, 1967.

10. R. L Moore, B. J. Merrill, and R. C. Martineau, Modifications to the MELCOR Code for NSSR-1, ITER EDF to be issued in December 1996.

11.D. A. Petti et al., "Safety Analysis Results for ITER In-Vessel Los-of-Coolant Events," Journal of Fusion Energy, in press. 


\section{RISK ASSESSMENT}

\section{Researchers: L. C. Cadwallader - INEL; T. D. Marshall - Rensselaer Polytechnic Institute}

The Fusion Safety Program (FSP) leads the U.S. effort in using risk assessment in fusion experiment design to provide safety for the public, workers, and the environment. Risk assessment is a part of the safety design effort for the International Thermonuclear Experimental Reactor (ITER). Two important features of fusion risk assessment are system analysis and radiological dose assessment. FY 1996 progress in the system analysis facet of fusion risk assessment work, including a study of divertor integrity loss timing in loss of flow events, is discussed below.

\section{Major Accomplishments}

System Analysis. INEL researchers supported work on the initial version of the Non Site-Specific Safety Report (NSSR-1). Research focused on developing a method to estimate component repair times, ${ }^{1}$ and on obtaining estimates of failure rates and repair rates for components in the vacuum vessel system and primary heat transport systems. ${ }^{2}$

Several reliability studies were also performed to support the ITER design and safety assessment. One of these was the study of heat exchanger performance regarding fluid leaks from primary to secondary. ${ }^{3}$. Another was an actuarial study of flow rates from pipe breaks. ${ }^{4}$

During this fiscal year, attention returned to adding more data to the component failure rate data bank for supporting probabilistic safety analyses. Focusing on safety systems, reliability data on fire protection systems was collected. ${ }^{5}$ Some system failure rates are given in Table 3. Another study on failure rates of selected process sensors and personnel safety sensors applicable to fusion was performed. ${ }^{6}$ These data are currently in report form only, not in a spreadsheet or other electronically accessible means. Future work will be done to place these data into spreadsheet format. A technical paper on the state of the art for data estimation for fusion safety was presented. ${ }^{7}$ The data estimation techniques most widely used by fusion safety analysts are the inference and analyst judgment techniques.

Work is continuing to develop component failure rate information. These data are partitioned by failure mode, and component repair rates and downtimes are also included. These data will be used to support ITER operational reliability studies and any safety assessment activities. Data collection will continue at a modest pace. Some operational safety and reliability issues will also be addressed in FY 1997. The data compilation task compliments the International Energy Agency's cooperative task on development of a failure rate database for fusion experiments.

Phenomenological studies. An important area in risk and safety assessment is estimation of response times of safety equipment and the allowable timeframes for 
Table 3. Generic Reliability Data for Fire Suppression Systems.

\begin{tabular}{|c|c|c|}
\hline $\begin{array}{l}\text { Type of } \\
\text { System }\end{array}$ & $\begin{array}{l}\text { Failure } \\
\text { Probability } \\
\text { per } \\
\text { fire demand }\end{array}$ & $\begin{array}{l}\text { Spurious } \\
\text { Actuation } \\
\text { Frequency } \\
\text { per year }\end{array}$ \\
\hline $\begin{array}{l}\text { Wet pipe } \\
\text { sprinkler }\end{array}$ & $\begin{array}{l}1 E-02 \\
\text { ef }=4.7\end{array}$ & $\begin{array}{l}5 E-03 \\
e f=5\end{array}$ \\
\hline $\begin{array}{l}\text { Dry pipe } \\
\text { sprinkler }\end{array}$ & $\begin{array}{l}2 \mathrm{E}-01 \\
\mathrm{ub}\end{array}$ & $\begin{array}{l}3 E-02 \\
e f=5\end{array}$ \\
\hline $\begin{array}{l}\text { Preaction } \\
\text { sprinkler }\end{array}$ & $\begin{array}{l}2 \mathrm{E}-01 \\
\mathrm{ub}\end{array}$ & $\begin{array}{l}1 E-04 \\
e f=10\end{array}$ \\
\hline $\begin{array}{l}\text { Deluge } \\
\text { sprinkler }\end{array}$ & $\begin{array}{l}1 \mathrm{E}-02 \\
\text { ef }=4.7\end{array}$ & $\begin{array}{l}1 \mathrm{E}-03 \\
\mathrm{ub}\end{array}$ \\
\hline $\begin{array}{l}\text { Halon } \\
\text { flooding }\end{array}$ & $\begin{array}{l}5 E-02 \\
\text { ef }=1.6\end{array}$ & $\begin{array}{l}5 E-03 \\
\text { ef }=5\end{array}$ \\
\hline $\begin{array}{l}\mathrm{CO}_{2} \\
\text { flooding }\end{array}$ & $\begin{array}{l}9 \mathrm{E}-03 \\
\text { ef }=2.6\end{array}$ & $\begin{array}{l}5 E-03 \\
e f=5\end{array}$ \\
\hline Dry chemical ${ }^{\mathrm{a}}$ & $\begin{array}{l}4 \mathrm{E}-01 \text { to } \\
6 \mathrm{E}-03 \\
\text { ef }=3.9\end{array}$ & ef $=5$ \\
\hline
\end{tabular}

note: "ef" stands for error factor, the quotient of the $95 \%$ upper bound divided by the average failure rate. " $u b$ " stands for upper bound failure rate.

a. Dry chemical systems have had widely varying reliability values due to nozzle clogging upon release and powder compaction while in standby.

adequate equipment response. In an experiment program at Sandia National Laboratory, ${ }^{8}$ work has been performed to estimate the time to ITER divertor tube burnout under simulated loss of flow conditions. These data are intended to give fusion designers an approximate idea of the response time ITER plant engineers and operators will have to successfully detect the onset of a loss of flow and safely shut down the plasma. This information is crucial to ensure that the typical ITER divertor plate can safely handle the thermal challenges of a loss-of-flow accident (LOFA).

Under normal ITER-like conditions, divertor tube burnout time is $32 \mathrm{~s}$ in a LOFA. This time suggests that if plant personnel require more than $32 \mathrm{~s}$ for a response, then additional active circulation devices (such as standby emergency pumps) or other measures are necessary to ensure that the typical ITER divertor plate will not fail and allow water admission into the vacuum vessel. Further tests are required to verify this $32-\mathrm{s}$ time estimate for the given inlet conditions.

\section{Future Activities}

We shall continue to support the ITER JCT and the U.S. Home Team with risk analysis, including initiating event and accident sequence identification, failure modes and effects analysis, component failure rate and repair rate estimation and compilation, and any radiological dose assessments that might be needed for NSSR-2 and other safety requirements.

If resources permit, additional work in modeling an aquatic food chain for use in a radiological dose code will be undertaken. Other potential tasks include more reliability data analysis of data generated at the Tritium Systems Test Assembly.

The work on divertor tube modeling in loss of flow events is scheduled for completion at the end of FY 1997. 


\section{References}

1. L. C. Cadwallader, Determining Representative Hands-On Maintenance Times for ITER, ITER/US/96/TE/SA-01, February 23, 1996.

2. L. C. Cadwallader, Vacuum System and Primary Heat Transfer System Component Failure Rates and Repair Rates, ITER/US/96/TE/SA-05, March 28, 1996.

3. L. C. Cadwallader, Heat Exchanger Performance, ITER/US/96/EN/SA-03, April 29, 1996.

4. L. C. Cadwallader, Pipe Break Size and Leak Rate Experience, ITER/US/96/EN/SA-04, May 20, 1996.

5. L. C. Cadwallader, Fire Protection System Operating Experience Review for Fusion Applications, INEL-95/0396, December 1995; also presented at the ANS $12^{\text {th }}$ Topical Meeting on the Technology of Fusion Energy, Reno, Nevada, June 16-20, 1996.

6. I. C. Cadwallader, Reliability Estimates for Selected Sensors in Fusion Applications, INEL-96/0295, September 1996.

7. L. C. Cadwallader and T. D. Marshall, Component Reliability Data Estimation for Fusion Safety and Risk Assessment, ANS International Topical Meeting on Probabilistic Safety Assessment (PSA '96): Moving Toward Risk-Based Regulation, Park City, Utah, September 29 - October 3, 1996.

8. T. D. Marshall, R. D. Watson, J. M. McDonald, L. S. Wold, D. L. Youchison, and L. C. Cadwallader, Experimental Time To Burnout of a Prototypical ITER Divertor Plate During a Simulated Loss of Flow Accident, SAND96-2611, Sandia National Laboratories, to be published. 


\title{
FUSION SAFETY STANDARD DEVELOPMENT
}

\author{
Researchers: G. R. Longhurst, G. A. Dinneen, J. S. Herring, \\ and D. A. Petti - INEL; \\ D. J. Baker - WSRC; J. DeLooper - PPPL; M. J. Gouge - ORNL
}

In the past, fusion facilities have been small research facilities, and the risk to the public in the event of an accident was insignificant. With advent of the International Thermonuclear Experimental Reactor (ITER), however, the potential hazard is much more substantial. The radioactivity release potential scales with available energy sources, which in turn scale with total facility power. The specific inventory of radioactive material available for release in an accident scales with the tritium inventory and the neutron fluence the structures receive.

Because ITER and similar or successor facilities will be nuclear facilities, care in their design and operation must be comparable with those of other nuclear facilities. When persons responsible for safety of fusion facilities in the Department of Energy (DOE) Office of Fusion Energy Sciences (OFES) and in DOE laboratories began to examine how that could be done using the suite of DOE Rules, Orders, and Standards available, they found there was not a good fit. There was a need for more relevant safety documents with which to design and regulate fusion facilities.

DOE initiated efforts to develop a fusion safety document in 1993 with the formation of the Fusion Safety Steering Committee, which was at first comprised of only 13 members, mainly representatives of the various DOE laboratories with interests in fusion safety and representatives of OFES.
The committee was subsequently expanded to include a group of 21 Ex-Officio Members (all from DOE) and 15 "Other Reviewers" representing mostly universities and industries.

\section{Major Accomplishments}

During FY 1996, two DOE standards were completed, reviewed, and accepted by the fusion community: DOE-STD-6002-96, Safety of Magnetic Fusion Facilities Requirements, and DOE-STD-6003-96, Safety of Magnetic Fusion Facilities - Guidance. The principal writers, mostly members of the original group of 13 members, were from the Idaho National Engineering Laboratory (INEL), Oak Ridge National Laboratory (ORNL), Princeton Plasma Physics Laboratory (PPPL), and Westinghouse Savannah River Company (WSRC).

In addition, we wrote a handbook (Supplementary Guidance and Design Experience for the Fusion Safety Standards DOE-STD-6002-96 and DOE-STD-6003-95, Project Control No. SAFT0059) containing information and good design practices that were felt to be beyond the scope of the standards. This handbook was issued in draft form at the end of FY 1996 and will be issued in final form during FY 1997.

Requirements. The contents of DOE-STD-6002-96 are based on requirements 
found in Federal regulations, modified to reflect the fusion context. Safety philosophies, approaches, and requirements from radiation protection, fission, risk and reliability, space, and chemical technologies were examined. Those aspects that were appropriate for fusion were incorporated; those that needed to be modified were modified, and those that were not appropriate for fusion were omitted.

In two important areas, the committee determined that existing requirements were insufficient, and additional requirements were added. Those two areas are neither specifically DOE nor Federal requirements but are inclusions in the Safety Policy of the Requirements Standard that reflect community concern. They are (1) the requirement of no public evacuation for magnetic fusion facilities, and (2) the goal for minimization of the amount of fusion facility waste, especially waste characterized as high-level radioactive waste.

The "no public evacuation" requirement was strongly endorsed by the US Fusion Utility Advisory Group. This group consists of executives from the utilities industry and fusion developers. It was also endorsed by the ITER Steering Committee, US. This requirement is unique in the current $\mathrm{DOE}$ regulatory environment and may place specific constraints on facility confinement system or siting criteria.

The control of waste production such that fusion facility radioactive waste can be recycled or disposed of as low level waste is a long-term goal of fusion. Thus, minimization of the amount and activity of radioactive waste generated was included as a requirement in the design, selection of materials, and conduct of operations of a fusion facility. No quantitative objective was set due to the large gap between the performance of existing construction materials and the desired goal of no high-level waste.

Guidance. DOE-STD-6003-96, Safety of Magnetic Fusion Facilities - Guidance is, as the name indicates, guidance on how to achieve or implement the requirements set forth in the Requirements 'Standard, DOE-STD-6002-96, assuming DOE regulation for an engineering scale facility like ITER. Nothing in the guidance standard is intended to add to the requirements, only to indicate methods and processes that may be used to meet existing requirements. In that sense, it is subordinate to the requirements standard, DOE-STD-6002-96.

The guidance provides an acceptable but not necessarily unique way to implement the requirements for an experimental fusion facility such as ITER or a demonstration prototype (DEMO). This guidance would presumably be updated for eventual fusion power reactors, where results from preceding experimental devices would resolve outstanding material, plasma physics, and fusion technology issues.

\section{Future Activities}

When the handbook discussed previously is published, this activity will be complete. Any further actions, such as to elevate the Fusion Safety Standards to higher-level documents will depend on need, as dictated by the pace of fusion development in the U.S. 


\section{APPENDIX A}

Abstracts or Summaries of Fusion Safety Program Publications 


\section{INTERNATIONAL THERMONUCLEAR EXPERIMENTAL REACTOR DESIGN}

\section{An Overview of ITER Safety}

D. A. Petti and S. J. Piet, ANS 12th

Topical Meeting on the Technology of Fusion Energy, Reno, Nevada, June 1721,1996 (invited).

This paper presents an overview of safety in the International Thermonuclear Experimental Reactor (ITER) project midway through the Engineering Design Activities (EDA). We describe the safety strategy and approach used by the project. Then, we present project radiological release limits with the methodology used to determine if these release limits are met. We review the major safety functions and their implementation for ITER, previous results, and plans for upcoming safety and environmental analyses.

\section{Estimates Of Activation Product Transport Through ITER Confinement Barriers}

D. A. Petti and D. L. Hagrman, ANS 12th

Topical Meeting on the Technology of Fusion Energy, Reno, Nevada, June 1721, 1996

A simple "first principles" model has been developed to establish the level of activation product transport through ITER confinement barriers in both wet (steam) and dry (air) accident scenarios. The model accounts for steam condensation (wet scenarios only), aerosol agglomeration, gravitational settling, and leakage. Parametric studies have been performed for a range of aerosol particle sizes and mass densities expected by activation product mobilization. Recommended aerosol confinement release fractions for both wet and dry scenarios have been developed.

\section{Environmental and Safety Aspects of Fusion Facilities \\ D. A. Petti, American Power Conference 58th Annual Meeting, Chicago IL, April 1996 (invited).}

Fusion power has the potential to be a safe and environmentally sound energy source. Technological differences in fusion allow more flexibility to incorporate safety in the design than in fission. Fission, by its nature, results in long-lived, highly radioactive fission products. In fusion facilities, however, radionuclide inventories will be dominated by tritium fuel that collects on and within internal structures, and activation products produced in the structures whose hazard depends strongly on material choice. Thus, safety conscious selection of materials can result in minimization of toxic materials, activation product and tritium inventories, and stored energies. For fusion, careful selection of materials can greatly reduce potential hazards and go a long way toward the prevention of accidents which is the first level of the defense in depth principle.

\section{Overview Of Safety And Environmental Issues For Inertial Fusion Energy S. J. Piet et. al., "6th IAEA Technical Committee Meeting on Developments in Fusion Safety, JAERI, Naka Research Establishment, October 21-25, 1996 (to be published in the Journal of Fusion Energy).}

This paper summarizes safety and environmental issues of Inertial Fusion Energy (IFE): inventories, effluents, maintenance, accident safety, waste management, and recycling. The fusion confinement approach 
among inertial and magnetic options affects how the fusion reaction is maintained and which materials surround the reaction chamber. The target fill technology has a major impact on the target factory tritium inventory. IFE fusion reaction chambers usually employ some means to protect the first structural wall from fusion pulses. This protective fluid or granular bed also moderates and absorbs most neutrons before they reach the first structural wall. Although the protective fluid activates, most candidate fluids have low activation hazard. Hands-on maintenance seems practical for the driver, target factory, and secondary coolant systems; remote maintenance is likely required for the reaction chamber, primary coolant, and vacuum exhaust cleanup systems. The driver and fuel target facility are well separated from the main reaction chamber.

\section{Source Term and Mobilization Assessment in NSSR-1}

S. J. Piet et. al., 6th IAEA Technical Committee Meeting on Developments in Fusion Safety, JAERI, Naka Research Establishment, October 21-25, 1996 (to be published in the Journal of Fusion Energy).

We describe the radioactive sources in the International Thermonuclear Experimental Reactor (ITER), summarizing source term information in the first Non-Site Specific Safety Report (NSSR-1). The most important sources are codeposited tritium, tritiated water, tokamak dust, and corrosion products. The codeposited tritium is limited to $1 \mathrm{~kg}-\mathrm{T}$; the total on-site tritium inventory in the Basic Performance Phase (BPP) is $4 \mathrm{~kg}$ -
T. Tritiated water concentrations are kept below $0.2 \mathrm{~g}-\mathrm{T} / \mathrm{m}^{3}$ in the divertor; other coolant loops have lower tritium concentrations. The in-vessel dust inventory is up to $100 \mathrm{~kg}-\mathrm{W}, 100 \mathrm{~kg}-\mathrm{Be}$, and $200 \mathrm{~kg}-\mathrm{C}$. The activated corrosion product inventory is kept below $10 \mathrm{~kg}$ per loop.

\section{Safety Analysis Results for ITER In- Vessel Loss of Coolant Events} D. A. Petti, B. J. Merrill, S. T. Polkinghorne, L. C. Cadwallader and R. L. Moore, 6th IAEA Technical Committee Meeting on Developments in Fusion Safety, JAERI, Naka Research Establishment, October 21-25, 1996 (to be published in the Journal of Fusion Energy).

A number of postulated in-vessel loss of coolant accidents (LOCAs) associated with the first wall and baffle cooling systems of the ITER detailed design have been analyzed for the ITER Non-site Specific Safety Report (NSSR-1). A range of break sizes from one first wall tube break $\left(1.57 \times 10^{-4} \mathrm{~m}^{2}\right)$ to damage to all in-vessel components $\left(0.6 \mathrm{~m}^{2}\right.$ break) have been examined. These events span the ITER event classification from likely events to extremely unlikely events. In addition, in-vessel pipe breaks in combination with bypass of the two confinement barriers through a generic penetration have been examined. In all cases, when the vacuum vessel pressure suppression system is activated, most of the radioactive inventory is carried to the suppression pool where it remains for the duration of the event. Releases in these events are well within ITER release limits. 


\section{TRITIUM SAFETY}

Tritium Inventory Estimate for MetalFaced Plasma-Facing Components in ITER

G. R. Longhurst, ITER/US/96/TE/SA-9 REV. 02, August 2, 1996

Recent developments in understanding of the processes taking place in beryllium surfaces exposed to plasma ions have warranted a revisitation of the estimates for tritium inventory in ITER plasma-facing components (PFCs). Further, the ITER Joint Central Team has issued a Safety Analysis Data List (SADL) containing design information to be used in the Non-site Specific Safety Report (NSSR-1). The present report outlines theoretical and experimental results that have changed our perception of the processes important to tritium inventory in metal-faced PFCs and the results of new calculations of what that inventory may be. Recently published experimental data on the Tritium Plasma Experiment at Los Alamos National Laboratory have shown that under ITER-like plasma conditions, beryllium surfaces saturate, making uptake of hydrogen species almost independent of ion flux. Reviews of Russian results and modeling the Los Alamos experiments using the TMAP4 code suggests surface layers develop high porosity with the result that implanting ions and atoms are readily returned to the plasma once saturation has been achieved. Using the same transport parameters that fit the experimental data, estimates were made of the inventory and permeation in ITER plasma-facing components after $3 \times 10^{6} \mathrm{~s}$ of operating time. These estimates indicate a tritium inventory in the metal-face PFCs (first wall, startup limiter, baffles, upper strike plate, wings and dome) may be only a few tens of grams rather than the few hundreds of grams estimated for those components in prior years. Permeation, likewise, is estimated to be very small over that same period, only a fraction of a curie per day. These estimates are subject to uncertainties involving implantation depth and distribution, operating temperatures, and effects of neutron irradiation, but the variation is expected to be less than a factor of ten from the estimated values. Appendices describe the analysis procedure in detail and the novel application of features of the TMAP4 Code to include the effects of surface saturation and erosion from plasma sputtering. There is still a need for experimental data to evaluate the existence and effects of surface oxide and/or carbide films on tritium retention and release.

\section{Initial Deuterium Implantation Thermal Desorption Experiments for $\mathrm{Be}$ and $\mathrm{C}$ - Coated Be \\ R. A. Anderl, M. A. Oates, R. J. Pawelko, G. R. Longhurst, ITER/US/96/TE/SA-13, Rev. 2, August 7, 1996.}

This report documents modifications made to the deuterium ion implantation system at the Idaho National Engineering Laboratory and presents initial results of deuterium implantation/thermal desorption studies for Be and $\mathrm{C}$-coated Be samples. The work specifically addresses issues that concern tritium transport behavior in complex material layers that are formed because of material erosion, transport, and redeposition in a tokamak that contains different types of PFC materials. Modifications to the implantation system entailed design and installation of a new fast, response target heater assembly, an auxiliary vacuum chamber 
equipped with a fast-response sample heater and quadrupole mass spectrometer for thermal-desorption studies, and a versatile sample handling system to move samples, in vacuum, between the target chamber, the desorption chamber and a loadlock chamber. A detailed description of this system modification is given in this report and the results of shakedown tests with the system are summarized. Initial deuterium implantation/thermal desorption studies are reported here for bare $\mathrm{Be}$ samples and $\mathrm{Be}$ samples coated with different thicknesses of carbon. These studies entailed preparation and characterization of $\mathrm{Be}$ samples coated with $C$ thicknesses of 100,500 and $1000 \AA$ of C. Heat-treatment of a Be sample coated with $C$ to a thickness of $\sim 100 \AA$ revealed that exposure to a temperature of $400^{\circ} \mathrm{C}$ under vacuum conditions was sufficient to cause significant diffusion of $\mathrm{Be}$ through the $\mathrm{C}$ layer, resulting in more $\mathrm{Be}$ than $\mathrm{C}$ (depletion of $\mathrm{C}$ ) at the surface, comparable concentrations of $\mathrm{C}$ and $\mathrm{Be}$ in the bulk of the coating layer, and $\mathrm{O}$ pickup throughout the coating, possibly during application of the $C$. Deuterium implantation/thermal desorption experiments for a bare $\mathrm{Be}$ sample and for $\mathrm{Be}$ samples coated with $\sim 500 \AA$ and $\sim 1000 \AA$ of carbon revealed differences in deuterium retention and post-implantation release behavior. For comparable implantation conditions (sample temperature of $400^{\circ} \mathrm{C}$ and an incident deuterium flux of $-6 \times 10^{19} \mathrm{D} / \mathrm{m}^{2}-\mathrm{s}$ ), the quantity of deuterium retained in the bare $\mathrm{Be}$ sample was less than in the C-coated sample. The majority of deuterium was released at a lower temperature for the bare $\mathrm{Be}$ than for $\mathrm{C}$ coated Be.

\section{Tritium Mobilization From ITER Plasma-Facing Components Under Specified Accident Conditions}

G. R. Longhurst, ITER/US/96/TE/SA-15, September 19, 1996.

As part of the source term estimate for the Non-Site-specific Safety Report (NSSR-1) for the International Thermonuclear Experimental Reactor (ITER), estimates were made of the mobilization of tritium from ITER plasmafacing structures under a sequence of accident conditions specified by the Safety Analysis and Assessment Group of the Safety, Environment, and Health Division at the ITER San Diego Design Cocenter. Tritium inventory in the various structures was assumed to be that determined in a previous analysis, but it did not include tritium bred in beryllium by neutrons. That non-bred inventory was $33 \mathrm{~g}$ for the structures considered while the bred inventory was estimated to be $64 \mathrm{~g}$. These are much lower than the $1.56 \mathrm{~kg}$ assumed as the baseline for the combined inventories in these same structures in the Safety Analysis Data List (SADL). Desorption estimates were made using the TMAP code with diffusion boundary conditions that depended on the material and thermal boundary conditions given in the definition of the accident scenario. In general, tritium mobilization was only a fraction of the non-bred inventory. In some cases it was about $75 \%$ mobilized while in others only a few percent was mobilized during the accident. In severe cases, all of the non-bred inventory was mobilized from beryllium-clad surfaces, but none of the cases modeled resulted in full inventory mobilization from tungsten-faced surfaces. The bred inventory tends to be released as a burst once a critical temperature is exceeded. 


\section{CHEMICAL REACTIVITY OF FUSION MATERIALS}

\section{System for Steam-Reactivity Measurements on Fusion-Relevant Materials \\ R. A. Anderl, R. J. Pawelko, M. A. Oates, G. R. Smolik, and K. A. McCarthy, 12th Topical Meeting on the Technology of Fusion Energy, Reno, Nevada, June 16- 20, 1996.}

This paper describes an experimental system developed to investigate steam-metal reactions important to fusion technology. The system is configured specifically to measure hydrogen generation rates and tritium mobilization rates for irradiated beryllium specimens that are heated and exposed to steam. Results are presented for extensive performance an scoping tests of the system to validate the experimental technique, to determine hydrogen-generation rate detection sensitivity, and to establish appropriate calibration methods. These results include measurements of the hydrogen generation rates for steam interactions with austenitic steel, tungsten and beryllium metal specimens. The results of these scoping tests compare favorably with previous work, and they indicate a significant improvement in hydrogen detection sensitivity over previous approaches.

\section{Chemical Reactivity of Tungsten Alloy, Copper Alloy, and Stainless Steel} Exposed to Steam

K. A. McCarthy, G. R. Smolik, and K. Coates, IAEA 6th Technical Committee Meeting on Developments in Fusion Safety, Naka, Japan, October 21-25, 1996.

In some Loss of Coolant Accident (LOCA) scenarios, water is injected into the vacuum vessel, exposing hot plasma-facing materials to steam. At high enough temperatures, the material oxidizes, producing hydrogen. The oxidation rate depends on the temperature of the material and the steam pressure. We have experimentally measured the hydrogen production rates of several materials. In this paper we present data on hydrogen production from tungsten alloy, pure tungsten, copper alloy, and stainless steel disks and powder exposed to steam. The hydrogen generation rates of these materials are generally lower than those of beryllium, carbon, and niobium.

\section{Steam-Chemical Reactivity Studies for Irradiated Beryllium \\ R. A. Anderl, R. J. Pawelko, M. A. Oates, G. R. Smolik, and K. A. McCarthy, IAEA 6th Technical Committee Meeting on Developments in Fusion Safety, Naka, Japan, October 21-25, 1996.}

This paper presents results of an experimental study to measure the chemical reactivity of irradiated $\mathrm{Be}$ specimens exposed to steam at temperatures ranging from $450^{\circ} \mathrm{C}$ to $1200^{\circ} \mathrm{C}$. Specific objectives included: (1) measurements of hydrogen generation rates for unirradiated Be control specimens exposed to steam, (2) measurements of hydrogen generation rates and tritium mobilization rates for irradiated $\mathrm{Be}$ exposed to steam (3) measurements of swelling of irradiated $\mathrm{Be}$ specimens annealed at temperatures ranging from $450^{\circ} \mathrm{C}$ to $1200^{\circ} \mathrm{C}$, and (4) a determination of the influence of irradiation effects on the chemical reactivity of $\mathrm{Be}$ exposed to steam. Specimens tested in this work were fully-dense Be cylinders $(0.76-\mathrm{cm}$ in diameter) fabricated with powder 
metallurgy techniques using Brush Wellman SP-200-F powder. Specimens were irradiated in the EBR-II at a nominal temperature of $400^{\circ} \mathrm{C}$ to a nominal fast neutron fluence $(>0.1$ $\mathrm{MeV}$ neutrons) of $6 \times 10^{22} \mathrm{n} / \mathrm{cm}^{2}$. In the experiments for irradiated $\mathrm{Be}$, swelling occurred at temperatures above $600^{\circ} \mathrm{C}$ and it increased to about $56 \%$ for an anneal temperature of $1,200^{\circ} \mathrm{C}$. Tritium and ${ }^{4} \mathrm{He}$ were released concurrently from specimens that were annealed at $800^{\circ} \mathrm{C}$ and above. Steam-Be reactivity measurements for the control specimens were consistent with previous work at temperature above $700^{\circ} \mathrm{C}$ and the new measurements extended the reactivity database down to $450^{\circ} \mathrm{C}$ where steam-reactivity was very small. Steamreactivity measurements for irradiated $\mathrm{Be}$ were comparable to control specimens for $600^{\circ} \mathrm{C}$ and below but they indicated a significant enhancement in the chemical reactivity of irradiated Be exposed to steam at a sample furnace temperature of $700^{\circ} \mathrm{C}$. 


\section{ACTIVATION PRODUCTS MOBILIZATION AND TRANSPORT}

\section{Estimates of Activation Product Transport Through ITER Confinement Barriers \\ D. A. Petti and D. L. Hagrman, 12th \\ Topical Meeting on the Technology of \\ Fusion Energy, Reno, Nevada, June 16- 20, 1996.}

A simple "first principles" model has been developed to establish the level of activation product transport through ITER confinement barriers in both wet (steam) and dry (air) accident scenarios. The model accounts for steam condensation (wet scenarios only), aerosol agglomeration, gravitational settling, and leakage. Parametric studies have been performed for a range of aerosol particle sizes and mass densities expected by activation product mobilization. Recommended aerosol confinement release fractions for both wet and dry scenarios have been developed.

\section{Design of a Medium-Scale Aerosol Source for ITER Safety Studies}

W. J. Carmack, J. E. O'Brien, G. R. Smolik, and K. A. McCarthy, 12th Topical Meeting on the Technology of Fusion Energy, Reno, Nevada, June 16-20, 1996.

The Fusion Aerosol Source Test (FAST) facility has been constructed to produce and measure aerosol material from 316 SS under a wide range of accident conditions. Details of the design and fabrication of the facility are presented including aerosol production and measurement equipment, effluent control, and data analysis. Preliminary testing has been completed and results from these preliminary tests are presented.

\section{Mobilization from Copper and Steel} Alloys

D. L. Hagrman, G. R. Smolik, K. A. McCarthy, and D. A. Petti, 12th Topical Meeting on the Technology of Fusion Energy, Reno, Nevada, June 16-20, 1996.

The mobilization of key components from Primary Candidate Alloy (PCA) Steel alloy have been measured with laboratory-scale experiments. The experiments indicate most of the mobilization from PCA steel is due to oxide formation and spalling but that the spalled particles are large enough to settle rapidly. Based on the experiments, models for the volatilization of iron, manganese, and cobalt from PCA steel in steam and molybdenum from PCA steel in air have been derived.

\section{Mobilization Processes from Vanadium Alloys During Oxidation} G. R. Smolik, K. A. McCarthy, D. L. Hagrman, K. Messick, and R. S. Wallace, 12th Topical Meeting on the Technology of Fusion Energy, Reno, Nevada, June 16-20, 1996.

The mobilization of several elements from vanadium alloys in flowing air was measured for temperatures between 600 and $1200^{\circ} \mathrm{C}$. Alloys with nominal compositions of V-5Cr-5Ti and minor amounts of calcium, scandium, and manganese added to simulate transmutation products were prepared by powder metallurgy. Mobilization of the three major alloying elements and the three minor additions was measured using a transpiration test method. Volatilization of sodium was modeled based upon equilibrium concentrations of this metal on the oxide scale 
resulting from the dissociation of $\mathrm{Na}_{2} \mathrm{O}$, the concentrations of vanadium oxides $\left(\mathrm{V}_{2} \mathrm{O}_{4}\right.$ and $\mathrm{V}_{2} \mathrm{O}_{5}$ ), and the oxygen content in the gas above the sample.

\section{Dose Due to Mobilization of Vanadium Alloy Activation Products}

K. A. McCarthy, G. R. Smolik, D. L. Hagrman, and D. A. Petti, 12th Topical Meeting on the Technology of Fusion Energy, Reno, Nevada, June 16-20, 1996.

This paper presents dose calculations due to oxidation-driven mobilization of a vanadium alloy, $\mathrm{V}-4 \mathrm{Cr}-4 \mathrm{Ti}$, exposed to air. We concentrate on air because it is highly unlikely that the vanadium alloy will be used with a water coolant. We calculate the offsite dose using data from transpiration tests together with information from activation calculations and the radiological hazard of the material from a dose code. We compare the early dose as a function of temperature from V-4Cr-4Ti with the early dose from tungsten, copper, $316 \mathrm{SS}$, and a low activation ferritic steel. The vanadium alloy dose is almost an order of magnitude lower than the dose from the other materials for the entire temperature range examined, $600-1200^{\circ} \mathrm{C}$.

\section{Experimental Investigation into Aerosol Mobilization Resulting From Fusion Reactor Disruptions}

J.P. Sharpe, M. A. Bourham, and J. G. Gilligan, 12th Topical Meeting on the Technology of Fusion Energy, Reno, Nevada, June 16-20, 1996.

An experimental system has been developed to study disruption-induced aerosol mobilization for fusion accident analysis. Using the SIRENS high heat flux facility at North Carolina State University, a hot vapor is formed by an ablation-controlled arc and expansion cooled into a glass chamber, where particle condensation and growth occurs. The particles are collected and analyzed for relevant transport properties (e.g. size distribution and shape). Particle characterization methods are discussed, and preliminary results based on simple analysis techniques are given.

\section{Dose Due to Mobilization of Tungsten Activation Products in Air}

K. A. McCarthy, G. R. Smolik, D. L.

Hagrman, and K. Coates, 19th

Symposium on Fusion Technology, Lisbon, Portugal, September 16-20, 1996.

We measured the mobilization of several elements from a tungsten alloy exposed to air over the temperature range $400-1000^{\circ} \mathrm{C}$. The alloy was prepared by powder metallurgy with minor amounts of $\mathrm{Re}, \mathrm{Ta}, \mathrm{Co}, \mathrm{Cu}, \mathrm{Fe}$, $\mathrm{Mn}$, and $\mathrm{Ni}$ added to represent probable alloying elements and transmutation products. We used the mobilization data to calculate the offsite dose, and compared that dose with copper alloy, stainless steel, low activation ferritic steel, and vanadium.

\section{An Overview of INEL Fusion Safety $R \& D$ Facilities}

K. A. McCarthy, G. R. Smolik, R. A. Anderl, and W. J. Carmack, IAEA 6th Technical Committee Meeting on Developments in Fusion Safety, Naka, Japan, October 2125, 1996.

The Fusion Safety Program at the Idaho National Engineering Laboratory is the lead laboratory for fusion safety in the United States. Over the years, we have developed several experimental facilities to provide data 
for fusion reactor safety analyses. We now have four major experimental facilities that provide data for use in safety assessments. The Steam-Reactivity Measurement System measures hydrogen generation rates and tritium mobilization rates in high-temperature (up to $1,200^{\circ} \mathrm{C}$ ) fusion relevant materials exposed to steam. The Volatilization of Activation Product Oxides Reactor Facility provides information on mobilization and transport and chemical reactivity of fusion relevant materials at high temperature (up to $1200^{\circ} \mathrm{C}$ ) in an oxidizing environment (air or steam). The Fusion Aerosol Source Test Facility is a scaled-up version of VAPOR. The ion-implantation/thermal-desorption system is dedicated to research into processes and phenomena associated with the interaction of hydrogen isotopes with fusion materials. In this paper we describe the capabilities of these facilities.

\section{Mobilization of 316 Stainless Steel From 500 to $800^{\circ} \mathrm{C}$ in Steam}

W. J. Carmack, G. R. Smolik, and K. A. McCarthy, IAEA 6th Technical Committee Meeting on Developments in Fusion Safety, Naka, Japan, October 21-25, 1996

This paper presents the results of steam exposure tests of 316 stainless steel in the Fusion Aerosol Source Test (FAST) facility. he tests were performed at temperatures of $500,600,700$, and $800^{\circ} \mathrm{C}$. These tests were conducted to measure the mobilized material resulting from the steam exposure conditions at each temperature. A steam volume flow rate of 21 to 25 STP-L/min was maintained in the test sections for a duration of $5 \mathrm{hr}$.

We compared the data obtained in these tests with data from the Volatilization of Activation Product Oxides Reactor (VAPOR) facility at $800^{\circ} \mathrm{C}$. The data obtained in the tests show the following:

1. There is a progressive increase of measured mass flux for $\mathrm{Fe}, \mathrm{Mo}, \mathrm{Mn}$, $\mathrm{Zn}$, and $\mathrm{Cr}$ with test temperature between $500^{\circ} \mathrm{C}$ and $800^{\circ} \mathrm{C}$.

2. Mass flux measurements from FAST and VAPOR agree within a factor of three for elements with volatile oxide or hydroxide species such as $\mathrm{Cr}$ and Mo.

3. Mass fluxes of elements associated with oxide spalling in VAPOR, mainly $\mathrm{Fe}$ and $\mathrm{Mn}$, were up to a factor of 90 lower in the FAST test than in the VAPOR test at $800^{\circ} \mathrm{C}$.

4. Detection limits in FAST were lower than those measured in VAPOR due to the larger surface area of the source in FAST tests.

\section{Volatilization from PCA Steel Alloy} D. L. Hagrman, G. R. Smolik, K. A. McCarthy, and D. A. Petti, 12th Topical Meeting on the Technology of Fusion Energy, Reno, Nevada, June 16-20, 1996

The mobilization of key components from Primary Candidate Alloy (PCA) steel alloy have been measured with laboratory-scale experiments. The experiments indicate most of the mobilization from PCA steel is due to oxide formation and spalling, but that the spalled particles are large enough to settle rapidly. Based on the experiments, models for the volatilization of iron, manganese, and cobalt from PCA steel in steam and molybdenum from PCA steel in air have been derived. 


\section{FUSION SAFETY COMPUTER CODE DEVELOPMENT}

Short Term Hydrogen Production Issues for ITER

M. J. Gaeta, B. J. Merrill, H.-W. Bartels, L. Topilski, submitted to Fusion

Technology.

The possibility of beryllium-steam reactions during severe accidents in the International Thermonuclear Experimental Reactor (ITER) is a safety concern because the hydrogen produced from these reactions could pose a flammability or detonation hazard. The physical mechanisms governing the production of hydrogen are examined and the sequence of events during a postulated exvessel Loss-of-Coolant-Accident (LOCA) are presented. A MELCOR simulation of an exvessel LOCA with simultaneous failure of the plasma shutdown system indicates that an invessel breach of the coolant system due to first wall melt through occurs. For the ITER Interim first wall/shield blanket (FW/SB) design, this accident results in about $67 \mathrm{~kg}$ of hydrogen being produced. A similar simulation for the divertor predicts only 0.3 $\mathrm{kg}$ of hydrogen because of additional cooling experienced by the divertor during the blowdown of coolant into the vacuum vessel. There is evidence to indicate that beryllium evaporation from the $\mathrm{FW}$ at a surface temperature of $1,373 \mathrm{~K}\left(1,100^{\circ} \mathrm{C}\right)$ is enough to cause plasma termination through beryllium evaporation. This plasma termination occurs prior to FW melting and could minimize or eliminate significant hydrogen production. Sensitivities studies were performed by varying the $\mathrm{FW}$ temperature at which plasma termination and in-vessel breach occurs for an ex-vessel LOCA scenario. This study shows that if the plasma is terminated before $150 \mathrm{~s}$ (i.e., a maximum $\mathrm{FW}$ temperature of $1,050 \mathrm{~K}$ $\left(777^{\circ} \mathrm{C}\right)$ ) after the ex-vessel LOCA, the amount of hydrogen generated is about $1 \mathrm{~kg}$ which is well below the flammability limit of $10 \mathrm{~kg}$ and gives a reasonable margin for model uncertainty. Other sensitivity studies using the FW/SB model indicated a relatively weak dependence of the hydrogen produced on invessel and ex-vessel breach size. In addition, a $60 \%$ reduction in coolant inventory resulted in only a one third decrease in hydrogen production from the base case.

\section{CHEMCON 3.1: Modeling Improvements, Verification and Applications}

M. J. Gaeta, B. J. Merrill, Hans-Werner Bartels, ANS 12th Topical Meeting on the Technology of Fusion Energy, Reno, NV, June 16-20, 1996.

This paper describes the recent modeling enhancements to the CHEMCON code that allow more accurate post-LOCA calculations to be performed for the ITER project. Verification activities performed on select models are also detailed. As part of these activities, a method of approximating multidimensional conduction and radiation effects in the one-dimensional CHEMCON code is given.

\section{MELCOR Aerosol Transport Module Modifications for NSSR-1}

B. J. Merrill and D. L. Hagrman, INEL/960081 , March 20, 1996.

This report describes modifications of the MELCOR computer code aerosol transport module that will increase the accuracy of calculations for safety analysis. of the International Thermonuclear Experimental Reactor (ITER). The modifications generalize 
aerosol deposition models to consider gases other than air, add specialized models for aerosol deposition during high speed gas flows in ducts, and add models for re-suspension of aerosols that are entrained in coolants when the coolants flash. Particular attention has been paid to the adhesion of aerosol particles once they are transported to duct walls. The results of calculations with the modified models have been successfully compared to data from the Light Water Reactor Aerosol Containment Experiments (PACE) conducted by an international consortium at Hanford, Washington.

\section{Safety Analysis Results for Cryostat Ingress Accidents in ITER}

B. J. Merrill, L. C. Cadwallader, and D. A. Petti, 6th IAEA Technical Committee Meeting on Developments in Fusion Safety, Naka, Japan, October 21-25, 1996.

Accidents involving the ingress of air or water into the cryostat of the International
Thermonuclear Experimental Reactor (ITER) tokamak design have been analyzed with a modified version of the MELCOR code for the ITER Non-site Specific Safety Report (NSSR-1). The air ingress accident is the result of a postulated breach of the cryostat boundary into an adjoining room. MELCOR results for this accident demonstrate that the condensed air mass and increased heat loads are not a magnet safety concern, but that the partial vacuum in the adjoining room must be accommodated in the building design. The water ingress accident is the result of a postulated magnet arc that results in melting of a Primary Heat Transport System (PHTS) coolant pipe, discharging PHTS water and PHTS water activated corrosion products and HTO into the cryostat. MELCOR results for this accident demonstrate that the condensed water mass and increased heat loads are not a magnet safety concern, that the cryostat pressure remains below design limits, and that the corrosion product and HTO releases are well within the ITER release limits. 


\section{RISK ASSESSMENT}

Fire Protection System Operating Experience Review for Fusion Applications,

L. C. Cadwallader, INEL-95/0396, December 1995; also presented at the 12th Topical Meeting on the Technology of Fusion Energy, Reno, Nevada, June 16-20, 1996.

This report presents a review of fire protection system operating experiences from particle accelerator, fusion experiment, and other applications. Safety relevant operating experiences and accident information are discussed. Quantitative order-of-magnitude estimates of fire protection system component failure rates and fire accident initiating event frequencies are presented for use in risk assessment, reliability, and availability studies. Safety concerns with these systems are discussed, including spurious operation. This information should be useful to fusion system designers and safety analysts, such as the team working on the Engineering Design Activities for the International Thermonuclear Experimental Reactor.

\section{Reliability Estimates for Selected Sensors in Fusion Applications, L. C. Cadwallader, INEL-96/0295, September 1996.}

This report presents the results of a study to define several types of sensors in use, the qualitative reliability (failure modes) and quantitative reliability (average failure rates) for these types of process sensors. Temperature, pressure, flow, and level sensors are discussed for water coolant and for cryogenic coolants. The failure rates that have been found are useful for risk assessment and safety analysis. Repair times and calibration intervals are also given when found in the literature. All of these values can also be useful to plant operators and maintenance personnel. Designers may be able to make use of these data when planning systems. The final chapter in this report discusses failure rates for several types of personnel safety sensors, including ionizing radiation monitors, toxic and combustible gas detectors, humidity sensors, and magnetic field sensors. These data could be useful to industrial hygienists and other safety professionals when designing or auditing for personnel safety.

\section{Component Reliability Data Estimation} for Fusion Safety and Risk Assessment, L. C. Cadwallader and T. D. Marshall, presented at the International Topical Meeting on Probabilistic Safety Assessment (PSA '96), Park City, Utah, September 29 - October 3, 1996.

This paper describes several reliability estimation techniques available for predicting failure rates for advanced technology components, specifically magnetic fusion components. The techniques are given a concise overview that includes their best suited application, primary benefits, and noted shortcomings. From the list of six general estimation techniques, two are highlighted as being most practical for the analysis time and the design information restraints encountered by the safety analyst working in a fusion design program. The two techniques of choice are the inference and the analyst judgment techniques; with inference being the prime choice. The inference technique requires a fusion relevant database 
of component failure rates and currently this database exists only in a very limited form. However, efforts by the Idaho National Engineering Laboratory (INEL), the International Energy Agency (IEA), and the International Thermonuclear Experimental Reactor (ITER) design project are aimed at enlarging this limited database.

\section{Experimental Time To Burnout of A Prototypical ITER Divertor Plate During a Simulated Loss of Flow Accident,} T. D. Marshall, R. D. Watson, J. M. McDonald, L. S. Wold, D. L. Youchison, and L. C. Cadwallader, SAND96-2611, to be published.

The Loss of Flow Accident (LOFA) is a serious safety concern for the International Thermonuclear Experimental Reactor (ITER) because it has been suggested that greater than $100 \mathrm{~s}$ are necessary to safely shut down the plasma when ITER is operating at full power. In this experiment, the thermal response of a prototypical ITER divertor tube during a simulated LOFA was studied. The divertor tube is fabricated from oxygen-free highconductivity copper to have a square geometry with a circular coolant channel. The inner diameter of the coolant channel is 0.77 $\mathrm{cm}$, the heated length is $4.0 \mathrm{~cm}$, and the heated width is $1.6 \mathrm{~cm}$. The mockup does not feature any flow enhancement techniques, i.e., swirl tape, porous coating, or internal fins. One-sided surface heating of the mockup is accomplished through the use of the $30-\mathrm{kW}$ Sandia Electron Beam Test System. After reaching steady-state temperatures in the mockup, as determined by two K-type thermocouples embedded $0.5 \mathrm{~mm}$ beneath the heated surface, the circulation pump for the high temperature, high pressure coolant loop is manually tripped off and the coolant flow allowed to naturally coast down. Electron beam heating continues after the pump trip until the divertor plate's heated surface exhibits the high- temperature transient normally indicative of rapidly approaching "burnout." Experimental data show that timeto-burnout increases proportionally with increases in the initial (before the pump trip) inlet velocity and decreases proportionally with increases in the incident heat flux. 


\section{FUSION SAFETY STANDARDS}

DOE-STD-6002-96, Safety of Magnetic Fusion Facilities - Requirements

This Standard provides the requirements for developing design and operations envelopes to ensure safety of magnetic fusion facilities. Also, safety principles are established to provide a framework within which the requirements can be implemented to build safety into fusion facility design and operations.

Fusion facilities developers must comply with applicable requirements in public laws and the Code of Federal Regulations. Requirements from these sources, as they pertain to safety of fusion facilities, have been included or referenced here. In some instances, requirements deemed necessary to ensure safety of fusion facilities have not been adequately covered heretofore, so new requirements in those areas have also been included. These added requirements are only binding to the extent that this Standard is included in performance contracts. They are requirements for conformance to this Standard. Requirements set forth are intended to apply to facilities constructed after issuance of this document.

Requirements identified in the Standard are intended to be used in evaluation of safety in fusion facility design and operations. The safety principles enumerated here constitute direction on practices determined to be essential to safety in fusion facilities. Because of the variation in design specifics of facilities governed by the requirements in this document, flexibility is provided as to how requirements will be met and how principles will be implemented. Included in DOE-STD6003-96, Safety of Magnetic Fusion Facilities Guidance, is an identification of potential hazards, energy sources and potential anticipated operational occurrences and offnormal conditions that should be considered in assessing the safety of a specific fusion facility. The appendix to this Standard provides background information on key considerations in the development of DOESTD-6002-96 and DOE-STD-6003-96.

\section{DOE-STD-6003-96, Safety of Magnetic Fusion Facilities - Guidance}

This DOE Standard is approved for use by all DOE Components and contractors. It was developed by subject matter experts in the Fusion Safety Working Group under the general direction of the Office of Fusion Energy Sciences. It has been reviewed by the Fusion Safety Steering Committee with representation from DOE laboratories, contractors, and universities involved with magnetic fusion research as well as the end user of fusion power, the electric utility industry.

This Standard provides guidance to successfully achieve public and worker safety at magnetic fusion facilities. It is intended for use by managers, designers, operators and other personnel with safety responsibilities for such facilities. This Standard is concerned mainly with large fusion facilities such and the International Thermonuclear Experimental Reactor. Using a risk-based prioritization, the concepts presented here may also be applied to other magnetic fusion facilities. 


\section{Development of Fusion Safety Standards}

G. R. Longhurst et al., Fusion

Technology, Vol. 29, July 1996, pp. 627631.

Two new U.S. Department of Energy (DOE) standards have been prepared to assist in the design and regulation of magnetic fusion facilities. They are DOE-STD-6002-96 Safety of Magnetic Fusion Facilities - Requirements, and DOE-STD-6003-96 Safety of Magnetic Fusion Facilities - Guidance. The first standard sets forth requirements, mostly based on the Code of Federal Regulations, deemed necessary for the safe design and operation of fusion facilities and a set of safety principles to use in the design. The second standard provides guidance on how to meet the requirements identified in DOE-STD 6002-96. It is written specifically for a facility such as the International Thermonuclear Experimental Reactor (ITER) in the DOE regulatory environment. As technical standards, they are applicable only to extent that compliance with these standards is included in the contracts of the developers.

\section{Supplementary Guidance and Design Experience for the Fusion Safety Standards DOE-STD-6002-96 and DOE- STD-6003-96}

J. Stephen Herring, et al., to be published as a DOE-ER Handbook.

Two standards have been developed that pertain to safety of fusion facilities. These are DOE-STD-6002-06 Safety of Magnetic Fusion Facilities - Requirements, and DOESTD-6003-96 Safety of Magnetic Fusion Facilities - Guidance. The first of these identifies requirements that subscribers to that standard must meet to achieve safety in fusion facilities. The second contains guidance to assist in meeting the requirements identified in the first. This report provides additional documentation on good operations and design practices as well as lessons learned from the experiences of designers and operators of previous fusion facilities and related systems. It is intended to capture the experience gained in the various fields and pass it on to contractors of future fusion facilities as a means of enhancing success and safety.

The sections of this document are presented according to the physical local of the major systems of a fusion facility, beginning with the vacuum vessel and proceeding to those systems and components outside the vacuum vessel (the "Ex-vessel Systems"). The last section describes administrative procedures that cannot be localized to specific components. It has been tacitly assumed that the general structure of the fusion facilities addressed is that of a tokamak, though the same principles would apply to other magnetic confinement options. In what follows, use of the term "shall" has been avoided because this document is intended as advice and guidance only. It is not to be construed as regulatory in any way. In a similar vein, references to: safety-class or safety-significant structures, subsystems, and components should be viewed with the understanding that use of these designations, though not mandatory in the Requirements standard (DOE-STD-6002-96), are recommended in the Guidance standard (DOE-STD-6003-96). Again, the content of this document represents accumulated conventional wisdom of those who have experience building such systems and facilities. 
The material here is collected from a wide variety of sources. With the intent of capturing the information rather than making the product a polished document, there will be some variations in style and approach evident in the various sections. The authors felt allowing these would be a good stewardship of resources in the times of fiscal restraint and uncertainty in which this document was prepared. 


\section{APPENDIX B}

Abstracts of Fusion Safety Program ITER Engineering Design Files 


\section{TRITIUM SAFETY}

Initial Deuterium Implantation Thermal Desorption Experiments for $\mathrm{Be}$ and $\mathrm{C}$ Coated Be

R. A. Anderl, ITER/US/96/TE/SA-13, Revision 2, August 7, 1996.

This report documents modifications made to the deuterium ion implantation system at the Idaho National Engineering Laboratory and presents initial results of deuterium implantation/thermal desorption studies for $\mathrm{Be}$ and $\mathrm{C}$-coated $\mathrm{Be}$ samples. The work specifically addresses issues that concern tritium transport behavior in complex material layers that are formed because of material erosion, transport, and redeposition in a tokamak that contains different types of PFC materials. Modifications to the implantation system entailed design and installation of a new fast, response target heater assembly, an auxiliary vacuum chamber equipped with a fast-response sample heater and quadrupole mass spectrometer for thermal-desorption studies, and a versatile sample handling system to move samples, in vacuum, between the target chamber, the desorption chamber and a loadlock chamber. A detailed description of this system modification is given in this report and the results of shakedown tests with the system are summarized. Initial deuterium implantation/thermal desorption studies are reported here for bare $\mathrm{Be}$ samples and $\mathrm{Be}$ samples coated with different thicknesses of carbon. These studies entailed preparation and characterization of $\mathrm{Be}$ samples coated with $\mathrm{C}$ thicknesses of 100,500 and $1,000 \AA$ of $C$. Heat-treatment of a Be sample coated with $\mathrm{C}$ to a thickness of $\sim 100 \AA$ revealed that exposure to a temperature of $400^{\circ} \mathrm{C}$ under vacuum conditions was sufficient to cause significant diffusion of $\mathrm{Be}$ through the $\mathrm{C}$ layer, resulting in more $B e$ than $C$ (depletion of $C$ ) at the surface, comparable concentrations of $\mathrm{C}$ and $\mathrm{Be}$ in the bulk of the coating layer, and $\mathrm{O}$ pickup throughout the coating, possibly during application of the C. Deuterium implantation/thermal desorption experiments for a bare Be sample and for Be samples coated with $\sim 500 \AA$ and $\sim 1,000 \AA$ of carbon revealed differences in deuterium retention and post-implantation release behavior. For comparable implantation conditions (sample temperature of $400^{\circ} \mathrm{C}$ and an incident deuterium flux of $\sim 6 \times 10^{19} \mathrm{D} / \mathrm{m}^{2}-\mathrm{s}$ ), the quantity of deuterium retained in the bare $\mathrm{Be}$ sample was less than in the C-coated sample. The majority of deuterium was released at a lower temperature for the bare $\mathrm{Be}$ than for $\mathrm{C}$ coated Be.

\section{Tritium Inventory Estimate for Metal-} Faced Plasma-Facing Components in ITER

G. R. Longhurst, ITER/US/96/TE/SA-9 REV. 02, August 2, 1996.

Recent developments in understanding of the processes taking place in beryllium surfaces exposed to plasma ions have warranted a revisitation of the estimates for tritium inventory in ITER plasma-facing components (PFCs). Further, the ITER Joint Central Team has issued a Safety Analysis Data List (SADL) containing design information to be used in the Non-site Specific Safety Report (NSSR-1). The present report outlines theoretical and experimental results that have changed our perception of the processes important to tritium inventory in metal-faced PFCs and the results of new calculations of what that 
inventory may be. Recently published experimental data on the Tritium Plasma Experiment at Los Alamos National Laboratory have shown that under ITER-like plasma conditions, beryllium surfaces saturate, making uptake of hydrogen species almost independent of ion flux. Reviews of Russian results and modeling the Los Alamos experiments using the TMAP4 code suggests surface layers develop high porosity with the result that implanting ions and atoms are readily returned to the plasma once saturation has been achieved. Using the same transport parameters that fit the experimental data, estimates were made of the inventory and permeation in ITER plasma-facing components after $3 \times 10^{6} \mathrm{~s}$ of operating time. These estimates indicate a tritium inventory in the metal-face PFCs (first wall, startup limiter, baffles, upper strike plate, wings and dome) may be only a few tens of grams rather than the few hundreds of grams estimated for those components in prior years. Permeation, likewise, is estimated to be very small over that same period, only a fraction of a curie per day. These estimates are subject to uncertainties involving implantation depth and distribution, operating temperatures, and effects of neutron irradiation, but the variation is expected to be less than a factor of ten from the estimated values. Appendices describe the analysis procedure in detail and the novel application of features of the TMAP4 Code to include the effects of surface saturation and erosion from plasma sputtering. There is still a need for experimental data to evaluate the existence and effects of surface oxide and/or carbide films on tritium retention and release.
Tritium Mobilization From ITER Plasma-Facing Components Under Specified Accident Conditions G. R. Longhurst, ITER/US/96/TE/SA-15, September 19, 1996.

As part of the source term estimate for the Non-Site-specific Safety Report (NSSR-1) for the International Thermonuclear Experimental Reactor (ITER), estimates were made of the mobilization of tritium from ITER plasmafacing structures under a sequence of accident conditions specified by the Safety Analysis and Assessment Group of the Safety, Environment, and Health Division at the ITER San Diego Design Cocenter. Tritium inventory in the various structures was assumed to be that determined in a previous analysis, but it did not include tritium bred in beryllium by neutrons. That non-bred inventory was $33 \mathrm{~g}$ for the structures considered while the bred inventory was estimated to be $64 \mathrm{~g}$. These are much lower than the $1.56 \mathrm{~kg}$ assumed as the baseline for the combined inventories in these same structures in the Safety Analysis Data List (SADL). Desorption estimates were made using the TMAP code with diffusion boundary conditions that depended on the material and thermal boundary conditions given in the definition of the accident scenario. In general, tritium mobilization was only a fraction of the non-bred inventory. In some cases it was about $75 \%$ mobilized while in others only a few percent was mobilized during the accident. In severe cases, all of the non-bred inventory was mobilized from beryllium-clad surfaces, but none of the cases modeled resulted in full inventory mobilization from tungsten-faced surfaces. The bred inventory tends to be released as a burst once a critical temperature is exceeded. 
Every case studied here found more than the $1 \%$ mobilization assumed in the SADL.

\section{Modeling Transport Of Tritium And} Tritiated Water In Organic Coatings G. R. Longhurst, ITER/US/96/TE/SA-19, October 4, 1996.

Tritium and tritiated water may be released into a confinement or containment structure during an accident at ITER or another fusion facility. An important capability in analyzing such an accident is the estimation of the uptake and release of tritium and tritiated water by the walls of the facility, most of which will be covered with a paint or coating of some sort. The TMAP4 code is adequate for modeling such events provided good information is available on the transport properties of the tritiated species through the coatings and the substrate materials.

This document surveys measurements that have been made on the transport. properties of tritium and tritiated water in various organic materials contemplated or used as surface protectants for concrete and other structural materials. General findings are that although there are differences in the specific behaviors of the various materials with respect to tritium uptake and release, the transport properties tend to fall generally in the same band for the materials reported on. Organic coatings can reduce the uptake of tritiated water by up to two or three orders of magnitude, but they don't appear to be capable of completely eliminating the uptake. Indeed, there is a propensity for some coatings to acquire an inventory of their own, though the overall uptake by the coatings and the walls would be less than bare concrete. Where measured transport properties are available, they are presented here. Attention is also given to work done at the AECL Chalk River Laboratories where uptake in coated concrete specimens was measured but no transport properties can be definitively generated. 


\section{CHEMICAL REACTIVITY OF FUSION MATERIALS}

\section{Performance and Scoping Test Results for Steam-Metal Chemical Reactivity System \\ R. A. Anderl, ITER/US/96/TE/SA-17, October 17, 1996.}

This report documents performance and scoping tests that have been done with a new chemical reactivity system at the Idaho National Engineering Laboratory. This experimental system has been developed, in particular, for experiments to measure the hydrogen generation rates and tritium mobilization rates resulting from steam interaction with irradiated beryllium. The system comprises a flow-through, integrated assembly with components set up in an inertgas glovebox and in a Class-A laboratory hood. Hydrogen generation rates are obtained in two ways: from mass-spectrometer measurements of the gas composition in the system process line and from weight-gain measurements of the oxygen uptake in the samples. Tritium mobilization rats are obtained from measurements with an in-line ion chamber and from post-test analyses of tritium collected in ethylene-glycol traps and the condensed water. Performance tests have established the following typical system operational parameters: system pressure (675-685 torr), Ar carrier-gas flow rate $(100 \mathrm{sccm})$, steam generator temperature $\left(350^{\circ} \mathrm{C}\right)$, steam flow rate $(2,500 \mathrm{std} \mathrm{cc} / \mathrm{min}$ for water flow of $2 \mathrm{cc} / \mathrm{min}$ ), reaction chamber temperature $\left(25^{\circ} \mathrm{C}\right.$ to $\left.1,200^{\circ} \mathrm{C}\right)$, system response time ( $\sim 5 \mathrm{~min}$ for above flow rate), $\mathrm{H}_{2}$ detection sensitivity ( $3 \mathrm{ppm}$ of $\mathrm{H}_{2}$ in $\mathrm{Ar}$ ), and $\mathrm{H}_{2}$ generation-rate sensitivity $\left(\sim 2 \times 10^{-6} 1 / \mathrm{m}^{2}-\mathrm{s}\right)$. To validate the experimental technique, chemical reactivity scoping tests were done for different materials including: PCA austenitic stainless-steel discs, type 304 stainless-steel powder, a tungsten alloy (W96-14) disc, Be discs identical to those tested earlier at INEL, and Be cylindrical specimens that were control samples for the irradiated specimens that will be tested in the future. These tests demonstrated good consistency between quantities of hydrogen generated, as obtained from weight-gain and mass-spectrometer gas measurements. Results from tests on PCA (at temperatures from $700^{\circ} \mathrm{C}$ to $1,000^{\circ} \mathrm{C}$ ) and $\mathrm{W}$ (at $800^{\circ} \mathrm{C}$ ) were in good agreement with the results from previous work using a different system. A comparison of the results from stainless-steel disc and powder sample experiments at $800^{\circ} \mathrm{C}$ and $1,000^{\circ} \mathrm{C}$ showed that $\mathrm{H}_{2}$ generation rates from spherical powders can be estimated using effective surface areas derived from the spherical geometry. $\mathrm{H}_{2}$ generation results from tests on $\mathrm{Be}$ discs were consistent with the results from previous temperatures of $450^{\circ} \mathrm{C}$ to $1,200^{\circ} \mathrm{C}$. These results were in good agreement with the Be-disc experiments over applicable temperatures and they extended the rate information to much lower temperatures where steam-Be reactivity is small. The information compiled in this report is intended to serve as the quality assurance documentation for future steam-Be tests on irradiated $\mathrm{Be}$ specimens that will investigate the influence of neutron irradiation effects on steam-Be reactivity. 
Steam-Chemical Reactivity Experiments for Irradiated Be R. A. Anderl, ITER/US/96/TE/SA-18, October 17, 1996.

This report documents experiments that have been done at the Idaho National Engineering Laboratory to measure chemical reactivity of irradiated $\mathrm{Be}$ specimens exposed to steam. The specimens tested in this work were fully-dense $\mathrm{Be}$ cylinders irradiated in the EBR-II as part of the COBRA-1A2 Test. Two types of studies were done: annealing studies in which irradiated $\mathrm{Be}$ specimens were annealed at temperatures from $450^{\circ} \mathrm{C}$ to $1,200^{\circ} \mathrm{C}$ and (2) steamchemical reactivity experiments in which irradiated $\mathrm{Be}$ specimens were exposed to steam at temperatures from $450^{\circ} \mathrm{C}$ to $700^{\circ} \mathrm{C}$. The annealing experiments included immersion density measurements for irradiated specimens before and after annealing and measurements of the tritium and helium gasrelease behavior during specimen annealing. Based on the immersion-density measurements, these specimens experienced significant swelling as the anneal temperature was increased, from $13 \%$ at $700^{\circ} \mathrm{C}$ to $36 \%$ at $1,200^{\circ} \mathrm{C}$. Tritium and helium release behavior, for specimens annealing to $700^{\circ} \mathrm{C}$ and above, was characterized by release peaks or gasburst transients. We associate the gas burst with a surface-connected porosity network along the grain boundaries of the material that develops to relieve the internal gas pressure causing swelling. For experiments at $800^{\circ} \mathrm{C}$ and above, helium was observed to be released concurrently with the tritium, indicating that trapped tritium resides in helium bubbles in irradiated $\mathrm{Be}$. Comparable quantities of tritium were released from specimens annealed at $700^{\circ} \mathrm{C}$ and $800^{\circ} \mathrm{C}$, and this quantity was a factor of ten below that released during the higher temperature anneals. Steam-reactivity experiments for irradiated $\mathrm{Be}$ specimens included measurements with an in-line ion chamber, to obtain tritium mobilization rates resulting from the steam reaction. For experiments at $600^{\circ} \mathrm{C}$ and below, the observed $\mathrm{H}_{2}$ generation rates exhibited an initial transient, somewhat characteristic of parabolic steam-reactivity behavior. The results were similar to experiments on unirradiated $\mathrm{Be}$ control specimens, and the average $\mathrm{H}_{2}$ generation rates for irradiated and unirradiated $\mathrm{Be}$ were comparable for $600^{\circ} \mathrm{C}$ and below. We observed a significantly higher reaction rate for an irradiated $\mathrm{Be}$ specimen exposed to steam at $700^{\circ} \mathrm{C}$ than that for unirradiated samples at $700^{\circ} \mathrm{C}$. Measurements of the tritium and helium behavior indicated that, prior to steam exposure, the specimen swelled and developed a surface-connected porosity network. Because of a greater effective surface area from swelling and the development of the porosity network, the exothermic heat of reaction increased the sample temperature to $1,000^{\circ} \mathrm{C}$ or above, further accelerating the reaction. Consequently, most of the trapped tritium and helium were mobilized, and the reaction continued until the specimen was nearly consumed. Mobilized tritium was released approximately equally as elemental and oxide species. These results indicate that neutron irradiation of $\mathrm{Be}$ has a significant effect on steam-Be reactivity for neutron fluences comparable to that for the specimens tested in this work. 


\section{ACTIVATION PRODUCTS MOBILIZATION AND TRANSPORT}

\section{Aerosol Transport Behavior in ITER Penetrations: A Sensitivity Study D. A. Petti, ITER/US/95/TE/SA-34,} December 1995.

A parametric study has been performed using the AEROFLW code to determine aerosol transport behavior of $100 \mathrm{~kg}$ of $\mathrm{Be}$ dust through ITER penetrations (e.g., ECRF, ICRH, NBI) under representative accident conditions. Very large particles (> 10 microns) generally will not make it out of the facility. For the more easily transportable particles between 1 and 5 microns, the results are sensitive to the details of the penetration geometry and thermal hydraulics. Aerosol leakage is largest for the very small particles (0.1-0.5 microns) since inertial and gravitational effects are not very important for these sizes. However, aerosol agglomeration in the building and vacuum vessel which was not considered in the AEROFLW calculations will cause the particle size to increase and the overall leakage to decrease as inertial deposition effects begin to become important. Water condensation onto particles would have the same effect. Detailed MELCOR calculations will have to be done to verify this behavior.

Aerosol deposition from turbulent flow, inertial impaction at bends, and gravitational settling all reduce the aerosol leakage to the environment if ITER penetrations fail during an accident scenario. The most important parameters in determining the magnitude of the reduction are:

- aerosol particle size

- surface roughness of penetration duct

- time of the transient
- leak rate of building where penetration failure occurs.

In most cases, the 50-g category-IV groundlevel release is met. The highest releases were associated with the ICRH duct because of the smaller surface roughness volume available for deposition and the long blowdown times. The NBI blowdown is so fast that little release is calculated. The ECRF results are between these two extremes. For the smaller aerosol sizes, releases can exceed the $50 \mathrm{~g}$ category IV value, especially in smooth pipes for the constant pressure conditions examined here. However, it is important to recognize that it is highly unlikely that the dust will be uniform in size. The key issue is what fraction of the dust will be very small since that is the material that transports the furthest.

Of the limited parametric studies on leak rate, duct penetration length, and dust mass, only leak rate variations were linear as long as the time of the transient was not very long. The results for duct penetration length and dust mass were highly non-linear and were a strong function of the thermal hydraulics and surface roughness volume available for deposition in the duct. Individual calculations with AEROFLW are recommended to examine the exact sensitivities for specific cases.

Finally, it is important to note that there are three key uncertainties in the analysis that need additional research. First, the deposition model has had limited benchmarking at these high flow velocities. Furthermore, the model that accounts for filling up the surface roughness has had very limited validation against data. Finally, one scoping aerosol 
transport experiment has indicated that the adhesion characteristics of the aerosol particles may have an important effect on the transport/deposition behavior in pipes which has not been accounted for here. Simple experiments with different duct types connected to two volumes should be performed under these high velocity conditions to obtain data to verify the turbulent deposition model.

Second, it is absolutely critical to determine more information about the particle size distribution of aerosol sources in ITER. Current tokamak data indicate dust sizes will probably be in the 1 to 50 micron range. Corrosion products are expected to be $\sim 1$ micron. Material produced by oxidation driven volatilization will be submicron in size but is not expected to play an important role in the accident source term for ITER. The largest unknown is the particle size of material ablated from PFCs during a disruption. Theoretical calculations would suggest that such processes can produce a primary particle size distribution that is submicron in size, however some agglomeration is probably also likely. Experiments to be conducted by the US at North Carolina State University are critical to determine the particle size of material produced during a disruption.

\section{Performance Test Results of the FAST Apparatus \\ W. J. Carmack, G. R. Smolik, and J. E. O'Brien, ITER/US/96/TE/SA-08, June 1996.}

An experimental facility has been constructed and preliminary testing completed to produce and measure aerosol material from (unirradiated) SS 316 , copper, and tungsten materials typically found in fusion reactor systems. Performance testing has been completed. Details of the performance testing of the facility are presented including aerosol production and measurement results, process variables and limits, and data analysis.

The facility is capable of operation up to $1,200^{\circ} \mathrm{C}$ at atmospheric pressure. A variety of flow rates can be maintained in the experiment depending upon the orientation of aerosol instruments using argon, steam, air, or a combination of any two.

The system has been tested in five separate full performance tests. This report details the performance tests completed to date and the associated experiment procedures developed from the test experience. In addition, data obtained during performance tests including chemical analysis of collected material and plateout tube surfaces are. presented.

On June 27, 1996, this information was presented to the formal review committee. The signatures below indicate readiness to begin formal experiments as outlined in the test plan.

\section{Progress Report on Aerosol Mobilization From Disruptions J. P. Sharpe, ITER/US/96/TE/SA-11, July 29, 1996.}

Work is presently being performed on the SIRENS disruption simulator at North Carolina State University to study disruptioninduced aerosol mobilization and transport. High heat flux generated in SIRENS is of the order expected in ITER disruptions (i.e., $20-100 \mathrm{MW} / \mathrm{m}^{2}$ ). The electrothermal plasma source section of SIRENS has been modified to allow testing of ITER-relevant materials 
(copper, stainless steel, tungsten, and possibly beryllium). The high heat flux in the source section vaporizes the test material in a manner similar to disruption energy flux ablating wall material. The vaporized material is driven out of the source section and allowed to cool in an expansion volume, where aerosol particles nucleate upon vapor saturation. This mechanism of homogeneous nucleation id expected to occur in ITER following disruption vaporization. The expansion chamber used on SIRENS has been designed to give an expansion volume scaleable to that available in ITER.

Preliminary tests performed with copper indicate the formation of spherical particles. These particles have been collected on stainless steel buttons distributed along the surface of the expansion chamber. Scanning electron microscopic analysis of these buttons allows particle size determination and counting. The average particle size (count mean) for the first two tests were $2.11 \mathrm{~mm}$ and $7.75 \mathrm{~mm}$, respectively. These results are expectedly high because the counting technique used for the analysis did not properly account for the smaller particles $(<1-$ $0.1 \mathrm{~mm}$ ). Refinements of the counting technique will enable a more accurate determination of the resulting particle size distribution. Other independent particle size characterization techniques are being studied, primarily use of a quartz filter or a high temperature and pressure cascade impactor.

\section{Fusion Aerosol Source Test (FAST) Steam Exposure of 316 Stainless Steel W. J. Carmack and G. R. Smolik, ITER/US/96/TE/SA-20, October 1996.}

This engineering design file presents the results of three steam exposure tests of 316 stainless steel in the FAST facility. The three tests were conducted separately at temperatures of 500,600 , and $700^{\circ} \mathrm{C}$. A steam volume flow rate of 21 to $25 \mathrm{STP} \mathrm{L/min}$ was maintained in the test sections for a duration of $5 \mathrm{hr}$.

These three tests were conducted to measure the total volatilized and mobilized material resulting from the steam exposure conditions at each temperature. Tests were conducted in accordance with procedures outlined in the preliminary results engineering design file (Carmack et al., 1996). We have compared the data obtained in these tests with data from the VAPOR facility at $800^{\circ} \mathrm{C}$ and with scoping tests completed previously in the FAST facility. The data obtained in the three tests reported here show the following:

1. Progressive increases of measured mass flux for $\mathrm{Fe}, \mathrm{Mo}, \mathrm{Mn}, \mathrm{Zn}$, and $\mathrm{Cr}$ for temperatures ranging from $500^{\circ} \mathrm{C}$ to $800^{\circ} \mathrm{C}$.

2. Mass fiux measurements from FAST and VAPOR agreed within a factor of 20 for elements with volatile oxide or hydroxide species such as, $\mathrm{Cr}, \mathrm{W}$, and Mo

3. Elements associated with oxide spalling in VAPOR mainly $\mathrm{Fe}$ and $\mathrm{Mn}$, were a factor of 300 lower in FAST tests than in VAPOR tests at $800^{\circ} \mathrm{C}$.

4. Detection limits measured in FAST where lower than those measured in VAPOR due to the larger surface area used in FAST tests.

Some elements of interest are mobilized from components of the steam generation system. Incomplete mass balance data suggest that some of these elements may 
deposit out on the test section surface area at temperatures below $800^{\circ} \mathrm{C}$.

\section{Mobilization From Oxidation of a Tungsten Alloy in Air}

G. R. Smolik and K. Coates, ITER/US/96/TE/SA-2 (Rev. 1), September 26, 1996.

This change, Revision 1 , has been made to incorporate results obtained from oxidation tests performed at $400^{\circ} \mathrm{C}$ and from chemical analyses by induction coupled plasma-mass spectroscopy (ICP-MS), a method that allows lower detection limits to be obtained for some elements.

This Engineering Design File (EDF) presents the results of experiments performed in 1995-96 on a tungsten alloy exposed in air between 400 and $1,000^{\circ} \mathrm{C}$. The purpose of these tests was to measurement the mobilization of various elements from the alloy and the oxidation rate of the alloy. This experimental data supplements other data obtained from a similar alloy studied during 1988-1989. We have improved our analytical processes by lowering detection limits with inductively coupled plasma-atomic emission spectroscopy (ICP-AES) and with ICP-MS. Detection limits for mass fluxes of cobalt, tungsten, rhenium, and tantalum have been reduced by three orders of magnitude compared to those achieved in our earlier study. The detection limits for copper, iron, nickel, and manganese have been reduced by one to two orders of magnitude. We have also improved our methods for adjusting for inherent chemical contributions from test components and filters used to collect mobilized species. Consequently, we have been able to obtain statistically significant data for tungsten, iron, and nickel at the lowest temperature of $400^{\circ} \mathrm{C}$, for rhenium at $500^{\circ} \mathrm{C}$, and for tantalum and cobalt at $600^{\circ} \mathrm{C}$. Mobilization rates for the most volatile oxides, i.e., those of rhenium and tungsten, compared quite well with those from the earlier study where samples were heated with an induction furnace rather than in a tube furnace. We have constructed cumulative maximum flux plots for the various elements with respect to temperature. These are the plots that we recommend for fusion safety studies involving accidents with an ingress of air.

The oxidation rates of the alloy were examined by considering both normalized weight gain $\left(\mathrm{g} / \mathrm{cm}^{2}\right)$ and alloy consumption (mm). Oxidation rates from the two studies agreed quite well showing that the different methods of sample heating did not influence oxidation rates. Our data show that the tungsten alloy displays non-linear (probably cubic) oxidation kinetics at $800^{\circ} \mathrm{C}$. The data at $1000^{\circ} \mathrm{C}$ tends to show more linear kinetic behavior. The relationship for the oxidation rates of tungsten by Ong and Fassell; i.e.,

$d x / d t(m m / s)=(0.847) e^{(-12,170 / T)} P_{O_{2}}^{1 / 2}$

fits our data at 1,000 and $1,200^{\circ} \mathrm{C}$ very well. This relationship tends to over-predict oxidation rates at lower temperatures by about an order of magnitude. The departures at lower temperatures are caused by the authors use of linear kinetics and data from relatively short term tests by Ong and Fassell. 
Mobilization From Oxidation of a Tungsten Alloy in Steam

G R. Smolik and K. Coates, ITER/US/96/TE/SA-21, November 11, 1996.

This Engineering Design File (EDF) presents the mobilization results from experiments performed on a tungsten alloy exposed in steam between 400 and $1,200^{\circ} \mathrm{C}$ in 1996. These experimental results supplement other data we obtained from a similar alloy during 1988-89. We have improved our analytical processes such that we obtain lower detection limits with inductively coupled plasma-atomic emission spectroscopy (ICPAES) and with ICP-MS (mass spectroscopy). ICP-MS has allowed us to lower the detection limits for cobalt, rhenium, and tantalum by two orders of magnitude and copper and tungsten by more than one order of magnitude compared to those achieved in our earlier study. We have also improved our methods for adjusting for inherent chemical contributions from test components and filters used to collect mobilized species. Consequently, we have been able to obtain statistically significant data for tungsten, rhenium, cobalt, iron, and nickel at the lowest temperature of $400^{\circ} \mathrm{C}$ and to measure detectable amounts of the other elements, copper, manganese, and tantalum at $500^{\circ} \mathrm{C}$. Mobilization rates for the most volatile oxides, i.e., those of rhenium and tungsten, compared quite well with those from the earlier study showing that the mobilization of these elements were not significantly influenced by the heating method. The samples from the earlier study were heated with an induction furnace whereas the samples from the current study were tested in a tube furnace. We have combined the data from the two test series and constructed cumulative maximum flux plots for the various elements with respect to temperature. These are the plots that we recommend for fusion safety studies involving accidents with an ingress of steam.

\section{Activation Product Source Term Input for NSSR-1 (Rev. 1) K. A. McCarthy, ITER/US/96/TE/SA-10 (Rev. 1), November 15, 1996.}

This revised EDF differs from the original EDF in that new tungsten-steam mobilization data (down to $400^{\circ} \mathrm{C}$ ) are used in the dose calculations. Additionally, a comparison of tungsten, stainless steel, and copper doses is made.

The purpose of this EDF is to provide the activation product source term to be used by the JCT in preparing input for the Non Site Specific Safety Report - 1 (NSSR-1). The source term developed here is based on experiments carried out by the Fusion Safety Program at the Idaho National Engineering Laboratory (INEL). The information used to develop the source term was put into the spreadsheet developed for the source term input to ESECS. The spreadsheet now contains all the information for calculating the NSSR-1 activation product source term in addition to information used for ESECS. This allows the user to calculate a variety of cases, and provides flexibility so that the spreadsheet can be used to calculate new cases if parameters change.

We provide examples of the activation product source term for the three materials relevant to NSSR-1: tungsten, dispersionstrengthened copper, and 316 SS. Calculations for NSSR-1 can be done for three dose scenarios (four types of dose from each 
scenario: dose from plume passage, early dose, chronic dose without ingestion, and chronic dose with ingestion), two fluences (0.3 and $1.0 \mathrm{MWyr} / \mathrm{m}^{2}$ ), and two accident environments (air and steam). Additionally, the user can input his or her own activation calculation and/or dose information. 


\section{FUSION SAFETY COMPUTER CODE DEVELOPMENT}

\section{MELCOR Aerosol Transport Module Modifications for NSSR-1 \\ B. J. Merrill and D. J. Hagrman, ITER/US/96/TE/SA-3, February 21, 1996.}

We have completed modifications to the MELCOR code aerosol transport module that will increase the accuracy of this module for ITER safety analyses of accidents like lossof-cooling accidents (LOCAs) into the vacuum vessel. These accidents will resuspend material eroded from the first wall and divertor, and corrosion products in ITER's heat transport system (HTS) coolant. The modifications described in this EDF address aerosol deposition in gases other than air, turbulence and inertial aerosol deposition for high speed flows in ducts, and resuspension of aerosols that are entrained in coolants when these coolants flash. Most of these modifications were proposed in an assessment of the MELCOR code performed in 1994, and undertaken in 1995 after revising ITER Joint Central Team (JCT) Task Agreement S 81 TT 03 95-02028 FU, subtask 2, entitled: System Level Transient ThermalChemical Codes. These revisions were made because of changes in research and development (R\&D) priorities prompted by results from the Early Safety and Environmental Characterization Study (ESECS).

We have benchmarked these modifications against data from experiments conducted by the Electric Power Research Institute (EPRI) designated as large-scale light water reactor (LWR) aerosol containment experiments (LACE) and found excellent agreement. For high speed flows in pipes, our model predicts that $\sim 3 \%$ of the aerosol mass entering the LACE test pipe remains on the pipe walls in comparison with a measure value for LACE test $\mathrm{CB} 3$ of $1 \%$. When we extend our surface adhesion model to include gravitational settling, the predicted pipe aerosol mass retention drops to $1.2 \%$. If the deposited aerosol films are highly viscous, as was the case for LACE test LA1, our model predicts that $98.4 \%$ of the aerosol mass entering the LACE test pipe will remain on the pipe wall. The measured aerosol mass retention was reported as greater that $98 \%$. We have found good agreement between our model and the data from the LACE containment depressurization test LA5. MELCOR predicted pressures and temperatures that are within $6 \%$ of those measured by this test. In. addition, the peak concentration of aerosols re-suspended as a result of pool flashing was predicted to reach $0.58 \mathrm{mg} / \mathrm{m}^{3}$ compared to a measured value of $0.48 \mathrm{mg} / \mathrm{m}^{3}$.

However, even given the success of this benchmarking exercise, there are still some unanswered issues with respect to our modified MELCOR aerosol transport module. These issues primarily center around aerosol chemical characteristics and carrier gas conditions of the LACE experiments being different than those expected in ITER, and the accuracy of some the LACE measurements. As a consequence, we suggest that additional aerosol transport tests be performed to obtain data more characteristic of ITER accident conditions, and to improve the confidence level we have in our aerosol transport module. 


\section{A Preliminary ATHENA Model of the ITER Vacuum Vessel Heat Transport System \\ S. T. Polkinghorne and K. E. Carlson, ITER/US/96/TE/SA-07, May 9, 1996}

This EDF documents a preliminary ATHENA model of the ITER vacuum vessel heat transport system (VV-HTS). The model, which represents either of two independent cooling systems, simulates one-half of the vacuum vessel (every other sector), the pressurizer, the air-cooled heat exchanger, the pump, the flow control valve, and the interconnecting piping. Hydrodynamic volumes represent the coolant flow paths and heat structures represent the metal mass of piping and vacuum vessel components. Heat source tables define vacuum vessel heating rates under normal and off-normal conditions. A simple control system is used to establish the initial vacuum vessel flow rate, pressure, and inlet and outlet temperatures. The results from two checkout calculations (steady-state and transient loss-of-flow) demonstrate that the model functions as intended.

Design information for the heat transport loop was obtained from the Safety Analysis Data List (SADL), Version 1.1, dated March 31,1996 . As noted in the SADL, the pipe routing and physical layout of the VV-HTS is not yet fixed. Therefore, the ATHENA model described in this EDF is considered preliminary. The model is moderately detailed, consisting of 55 hydrodynamic volumes, 56 junctions, and 70 heat structures. As the VV-HTS evolves, a convergence study should be performed to ensure that the nodal layout is adequate. Although the current model is intended primarily for natural circulation analysis, it can easily be modified for loss-of-coolant accident (LOCA) analysis. Appendices A and B of this EDF are input listings of the base steady-state model and a transient restart deck, respectively. 


\section{RISK ASSESSMENT}

Determining Representative Hands-On Maintenance Times for ITER

L. C. Cadwallader, ITER/US/96/TE/SA-01, February 23, 1996.

This engineering design file (EDF) contains a discussion of methods available to estimate times for hands-on corrective maintenance tasks. The reciprocals of these times are the repair rates for the ITER components. The method of historical information will be used, that is, use of published maintenance time estimates for similar components will support this stage of ITER design. Maintenance repair rates will be entered into an Excel spreadsheet and then incorporated into the ITER Sequence Analysis Database (ISAD). ISAD will be used with the Software Toolkit for Advanced Reliability and Safety (STARS). STARS is the ITER code of preference to perform risk assessment calculations to support the Non Site-specific Safety Report (NSSR-1).

\section{Vacuum System and Primary Heat Transfer System Component Failure Rates and Repair Rates} L. C. Cadwallader, ITER/US/96/TE/SA05, March 28, 1996.

This engineering design file (EDF) contains estimated failure rates for the major components in the International Thermonuclear Experimental Reactor (ITER) vacuum system and the water coolant heat transfer systems. Rates of hands-on repair are also given. These data are described and referenced in this EDF, and they are entered into an Excel spreadsheet for use in the ITER Sequence Analysis Database (ISAD). The ISAD supports the Non Site-specific Safety Report (NSSR). These data are the best available at the present time, however, they must be reviewed periodically to verify continued applicability to the ITER design.

Heat Exchanger Performance

L. C. Cadwallader, ITER/US/96/EN/SA03, April 29, 1996.

This engineering design file provides information about heat exchanger operating experience, specifically failure modes and leakage performance. This work is in response to a specific request by the Joint Central Team (JCT) at the recent International Thermonuclear Experimental Reactor (ITER) Non Site-specific Safety Report (NSSR) meeting held in February 1996. Information about existing water-to-water heat exchangers is presented here. Heat exchangers are passive equipment items - there are no moving parts, no control signals, and they must only contain the process fluids and provide transfer of heat through their walls. Although they are passive equipment items, heat exchangers can experience several failure modes. These failure modes and heat exchanger performance issues that affect operational reliability are discussed here, including performance specifications, leakage criteria, operating experiences, and some maintenance issues.

\section{Pipe Break Size and Leak Rate Experience \\ L. C. Cadwallader, ITER/US/96/EN/SA- 04, May 20, 1996.}

This engineering design file provides information about power plant piping operating experience, specifically failure modes and leakage performance. This work is in response to a specific request by the Joint Central Team (JCT) in March 1996. 
Information about existing fission reactor piping is presented here. Most of the piping experiences recorded by regulatory bodies are not detailed enough to learn both the leak rate and the crack opening area. Most of the leak experiences are small, under $57 \mathrm{~L} / \mathrm{min}$. A few pipe breaks have resulted in large flow rates, over $300 \mathrm{~L} / \mathrm{min}$. Several guidelines for postulated leakage rates and crack sizes are discussed. The leak before break issue is also discussed. 